Social Welfare Quarterly, Vol 19, Summer 2019, No 73

تأثبيرين يرى از ديكران و التوى مصرف منزلت كرا در شهروندان

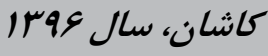

مقدمه: در دهه اخير، الكوى مصرف و توجه به /بعاد /جتماعى و فرهنكى رفتار مصرفكنناكان توجه بسيارى /ز صاحبنظران علوم را به خود معطوف

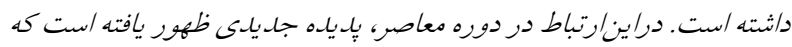
مصرف نه به سبب نياز، بلكه بنا به عو/مل ديخرى جون كسب برستيز، وجهه

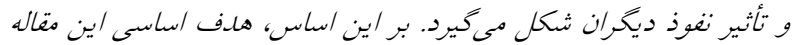

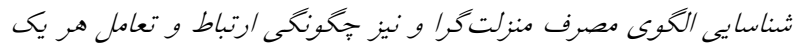

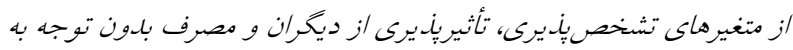

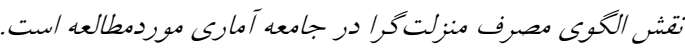

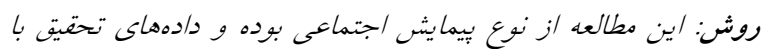

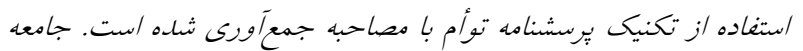

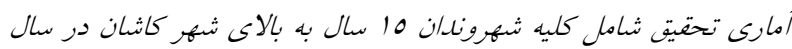

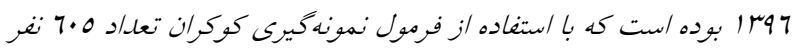
بهعنوان حجم نمونه تعبين و به روش تصادفى انتخاب و بررسى شلده/نل.

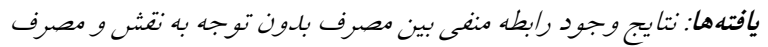

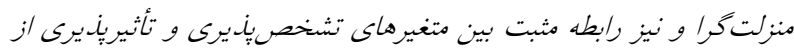

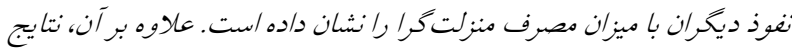
تحليل مسير ميز/ن تأثير هر يك /ز متغيرهاى مصرف بلون توجه به نتش،

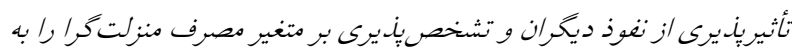

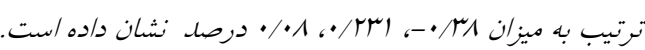
بحث: نتايج تحقيق با مباحث نظرى صاحبنظران و يافتههاى تحقيقات

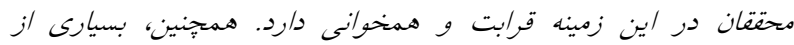

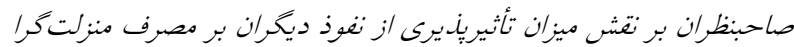

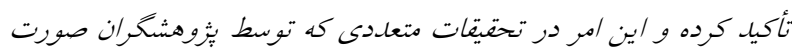

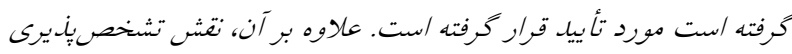

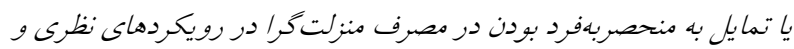
يثوهشى صاحبنظران و محقتان مختلف مورد تأييد قراركرفته /ست.

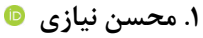

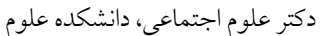

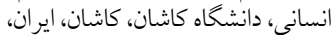

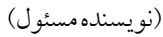
$<$ niazim@kashanu.ac.ir>

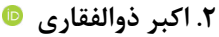
دكتر علوم سياسى، دانشكده علو علوم انسانى،

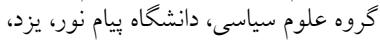
ايران

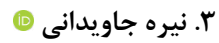

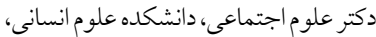

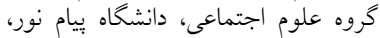
همدان، ايران

وازٔهاى كليدى:

الكوى مصرف، تأثيرين يرى /ز ديخران، تشخصئيرى، مصرف بلون توجه به تقش، مصرف منزلت

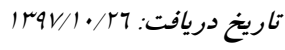

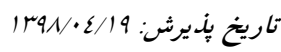




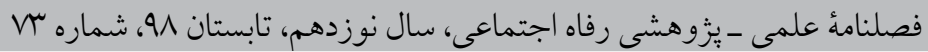

Social Welfare Quarterly, Vol 19, Summer 2019, No 73

\section{Relationship of the Consumer Susceptibility to Interper- sonal Influence and Pattern of Status Consumption: a Case Study on the Citizens of Kashan (2017)}

1- Mohsen Niazi i॰

Ph.D in Social Sciences, Faculty of Humanities, Kashan university, Kashan, Iran, (corresponding author) $<$ niazim@kashanu.ac.ir>

\section{2- Akbar Zolfaghari 두}

$\mathrm{Ph} . \mathrm{D}$ in Political Science, Faculty of Humanities, Department of Political Science, Payame Noor University, Yazd, Iran,

\section{3- Nayereh Javidani $\odot$} Ph.D in Social Sciences, Faculty of Humanities, Department of Social Sciences, Payame Noor University, Hamadan, Iran

\section{KeyWords:}

Acquisition of prestige, Consumer susceptibility to interpersonal influence, Pattern of consumption, Role-relaxed consumption, Status consumption

Received: 2019-01-16

Accepted: 2019-07-10

\section{Short Abstract}

In recent decades, the pattern of consumption has attracted the attention of the proprietors of social sciences and cultural studies. The data of the study were collected using interview questionnaire technique. The analysis of the data was done using the SPSS program. The statistical population of the study consisted of all citizens aged 15 years and older in Kashan in 2017. The sample size was based on the Cochran formula. Based on the results, there is a negative and significant relationship between role-relaxed consumption and status consumption and a positive and significant relationship between the variables of individualistic orientation, consumer susceptibility to interpersonal influence and amount of role-relaxed consumption. The results of Pearson correlation coefficient indicated a direct relationship between the two variables $(r=0.133$ and $\operatorname{sig}=0.001)$. The results show that the level of status consumption has been increased by raising the respondent's consumer susceptibility to interpersonal influence. The results also indicate that there is a direct and significant relationship between the level of consumer susceptibility to interpersonal influence and the level of status consumption. 


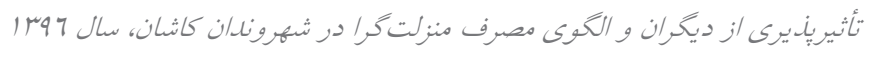

Relation of the Consumer Susceptibility to Interpersonal Influence and ...

\section{Extended Abstract}

Introduction: Introduction: In recent decades, the pattern of consumption and attention to the social and cultural dimensions of consumer behavior has attracted the attention of many of the experts of social sciences and cultural studies. In this regard, in the contemporary period, a new phenomenon has emerged that consumption is not needed, rather, it is due to other factors, such as the acquisition of prestige, the image and influence of others.

In Role-Relaxed Consumption, purchase of the product is for personal use only and attention to prestige or image is not transferable by product. These types of consumers are more concerned with the product's usefulness than its apparent aspect, and they have a low score in terms of susceptibility to interpersonal influence and disregard social expectations. Susceptibility to interpersonal influence means how much of a person's purchasing has been mentally and really influenced by others. High-impact people are more likely to be more influential when making purchasing decisions while individuals with low impact scores are more independent in the purchasing decision process. Accordingly, the basic purpose of this paper is to identify the pattern of status consumption as well as how to communicate and interact with each of the variables of individualistic orientation, the influence of individuals and consumption, regardless of their role on the dominant pattern of status consumption in the group of the participants studied in this research.

Method: This study was a social survey and the research data were collected using interview questionnaire technique. In this research, for the purpose of measuring each of the main variables, the related locutions have been used in the form of the Likert Scale. Validity and reliability of locutions have been examined in the preliminary and final tests by using Cronbach's Alpha Coefficient. After data collection, the analysis of the research findings was done using the SPSS computer program and needed statistical activities. In this study, the participants consisted of all citizens aged 15 years and older in Kashan in 2017. The sample size of this study was based on the Cochran sampling formula and its maximum application. The exact statistics of the sample size was estimated at 605 people among the citizens after distributing the preliminary copies of 


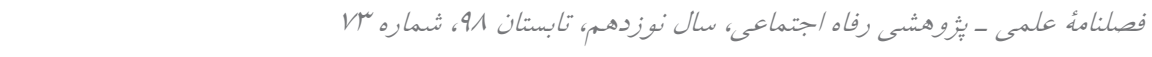

Social Welfare Quarterly, Vol 19, Summer 2019, No 73

the questionnaire and estimating the variance of the variables.

Results: The results of the research and the statistical activities using the Pearson correlation coefficient confirm that there is a negative and significant relationship between role-relaxed consumption and status consumption and a positive and significant relationship among the variables of individualistic orientation, consumer susceptibility to interpersonal influence, and the amount of role-relaxed consumption. In addition, the results of path analysis show that the variables of role-relaxed consumption, individualistic orientation, and consumer susceptibility to interpersonal influence were influenced by the status consumption variable; -38.8 and 23.1 percent, respectively.

The result of the study shows that the status consumption amount superfluity among role-relaxed consumption people in low, medium, and high level was $9.2 \%$, $25.3 \%$ and $65.5 \%$, respectively, and it decreased by increasing the amount of rolerelaxed consumption. The results of statistical activity using Pearson correlation coefficient $(r=0.417$ and sig $=0.000)$ indicate that there is a significant and negative relationship between the two variables at $99 \%$ confidence level. In examining the relationship between the degree of individualistic orientation and status consumption, the findings of the research indicate that, the level of status consumption would be increased by increasing the level of individualistic orientation in the manner that status consumption amount superfluity among individualistic orientation people with low frequency was at a rate of $34.1 \%$. This rate has increased up to $39.5 \%$ among the respondents with a high degree of individualistic orientation.

Discussion: The results of Pearson correlation coefficient indicated a direct relationship between the two variables $(r=0.133$ and sig $=0.001)$. The result of the study shows that, the level of status consumption among respondents has been increased by increasing the respondent's consumer susceptibility to interpersonal influence in the manner that status consumption amount superfluity among consumer susceptibility to interpersonal influence people with low frequency was at a rate of $32.2 \%$. This rate has risen up to $36.5 \%$ among respondents with a high impact level. The results of Pearson correlation coefficient $(r=0.233$ and $\mathrm{sig}=0 / 000)$ indicate that there is a direct and significant rela- 


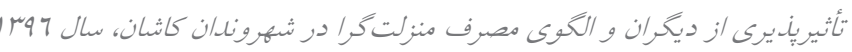

Relation of the Consumer Susceptibility to Interpersonal Influence and ...

tionship between the level of consumer susceptibility to interpersonal influence and the level of status consumption. This means that the level of status consumption increases by increasing the level of consumer susceptibility to interpersonal influence.

In sum, the research results are in agreement with the theoretical issues of the experts and the findings of previous research. Accordingly, the results of this study showed a negative relationship between the two variables including role- relaxed consumption and status consumption. Many scholars have also emphasized that the level of consumer susceptibility to interpersonal influence plays a very important role in the level of status consumption. In addition, the role of individualistic orientation in the status consumption has been confirmed in the theoretical and research approaches of various scholars. Other researchers in their respective research studies also have been approved the relationship between the two variables. According to the results of this study, product prestige is of great importance for sample individuals in choosing and using the goods. In this type of consumer style, the purpose of buying and consuming is acquisition of a status through high value-exchange. Especially in societies which the aristocracy and old rich people have been forced to pass the power to the new rich ones. In other words, in this consumer style, goods are valuable and important to create social differences and be regarded as agents of communication.

\section{Ethical Considerations}

\section{Funding}

In the present study, did not have any sponsors

\section{Authors' contributions}

All authors contributed in designing, running, and writing all parts of the research.

\section{Conflicts of interest}

This article does not conflict with other articles of my.

\section{Acknowledgments}

In this article, all rights relating to references are cited and resources are carefully listed 


\section{مقدمه}

در دنياى امروز مصرفكننده موجودى اجتماعى است كه با مصرف كالا در فرايند

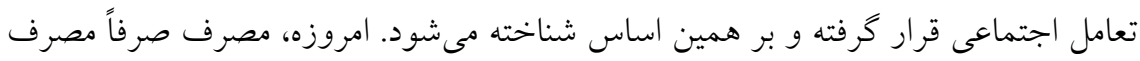

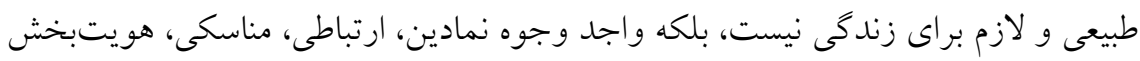

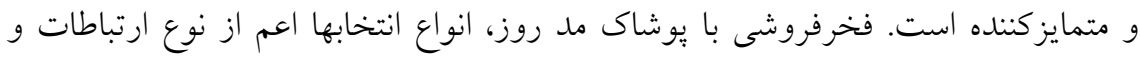
رفتارها، حضور در انواع مختلف فضاهاى عمومى و خصوصى، انجام فعاليتهاى فراغتى

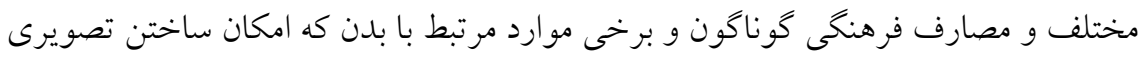

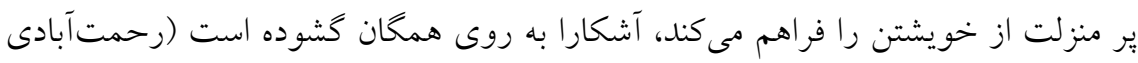

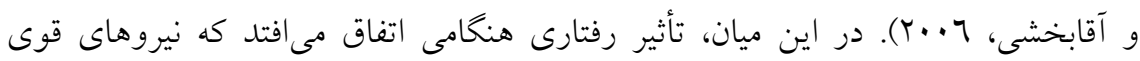

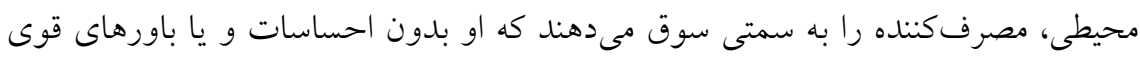

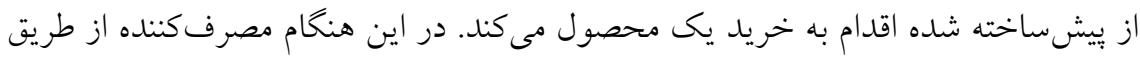

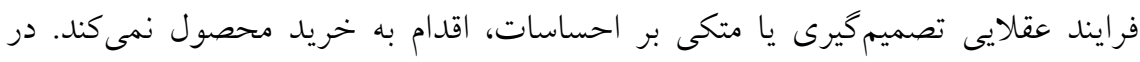

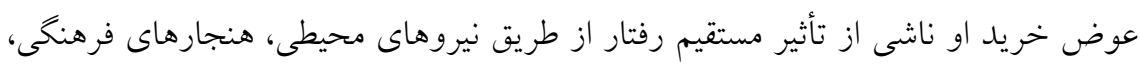
محيط فيزيكى و يا فشارهاى اقتصادى است.

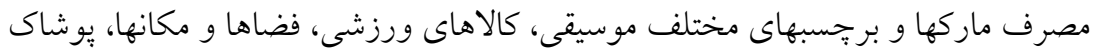

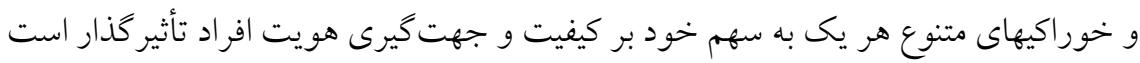

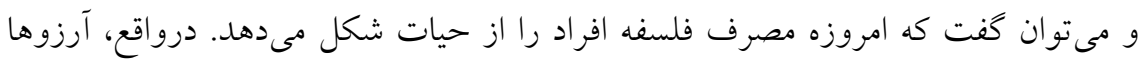

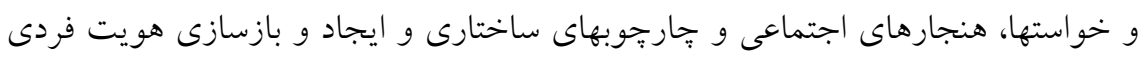

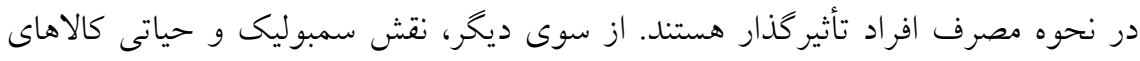

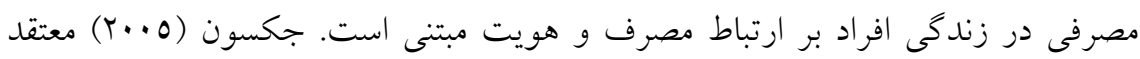

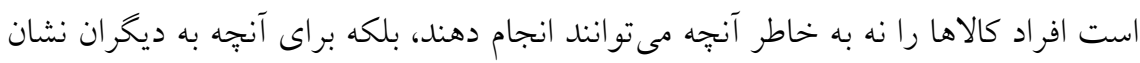


Relation of the Consumer Susceptibility to Interpersonal Influence and ...

مى دهند (درباره افراد و زندگى آنها، عشقشان، خواستهها، روابط، موفقيتها و شكستها)، ارج

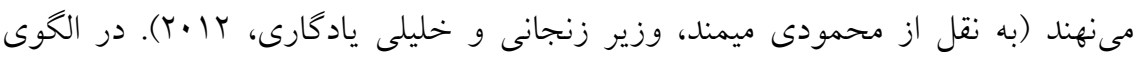

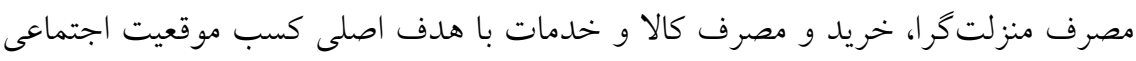

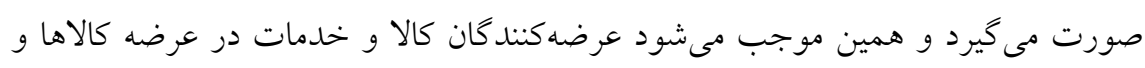

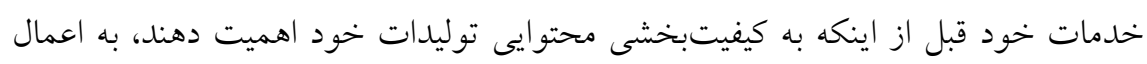

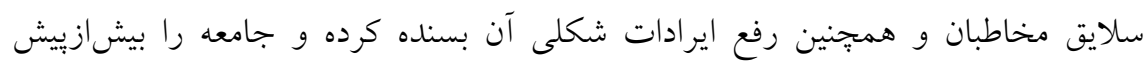

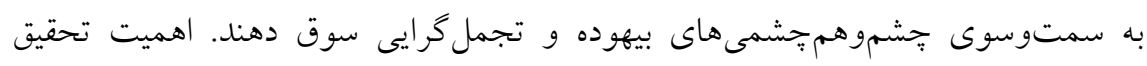

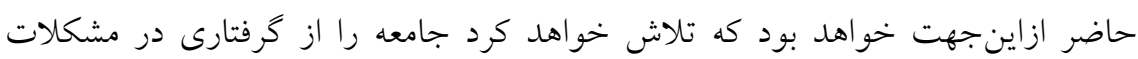
جشموهم جشمى ها و تجمل گر ايى و همجينين سوق يافتن به سمتوسوى كالاها و خدمات

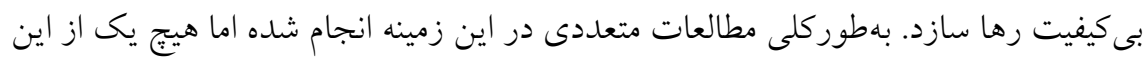

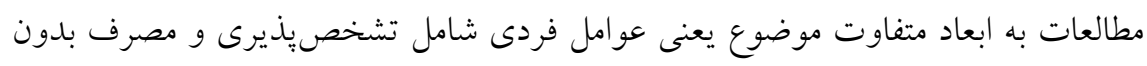

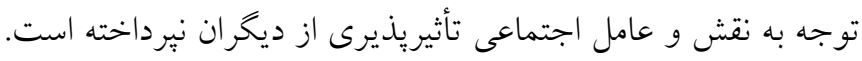

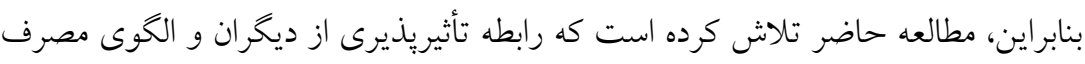

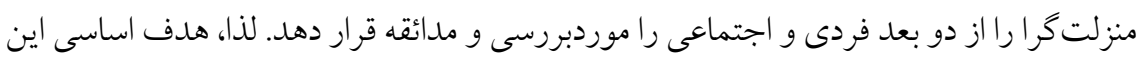

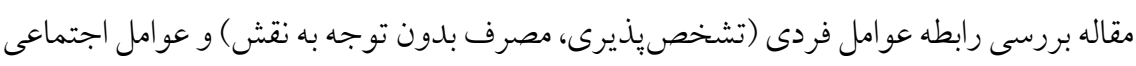

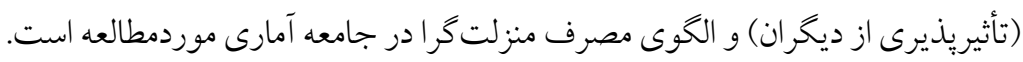

\section{جارجوب نظرى}

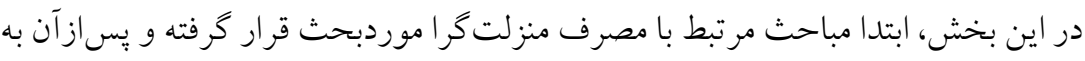

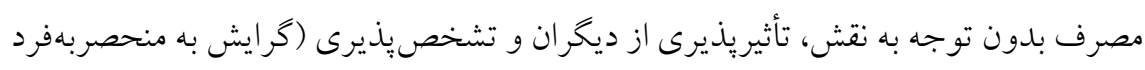

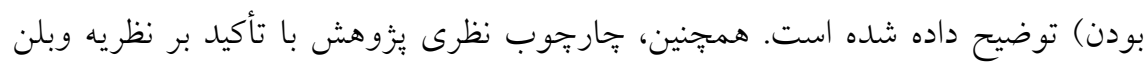
ارائه شده است. 


\section{الف) مصرف منزلتگرا}

بى ترديد هر فردى در اجتماع مى تواند نقشهاى متفاوتى را ايفا كند. درواقع جايگاه فرد

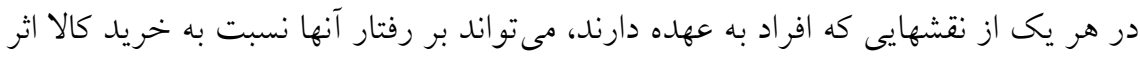

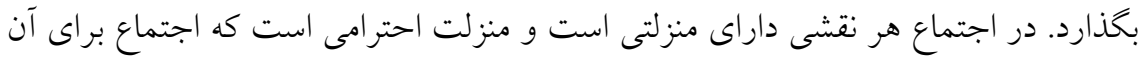

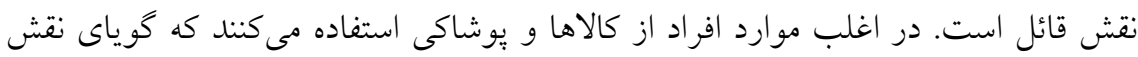

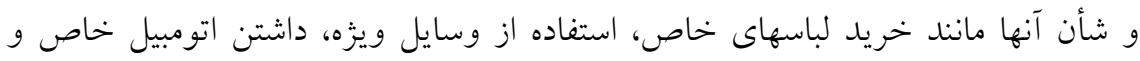

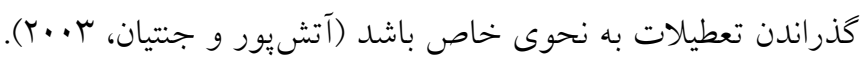
منزلت كرايى در مصرف' (SC) فرآيندى انخيزشى است كه افراد تلاش مى كنند از طريق مصرف محصولات مصرفى تجملى كه نمادى از مقام براى فرد و افراد مهم بيرامون او

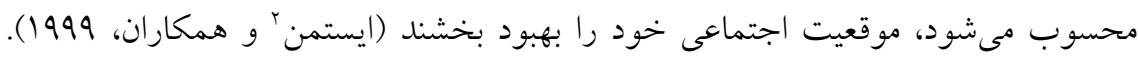

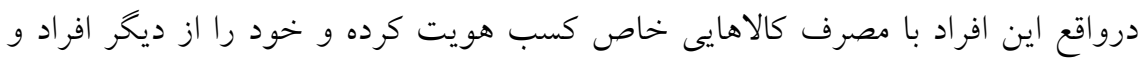

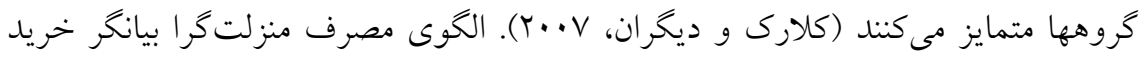

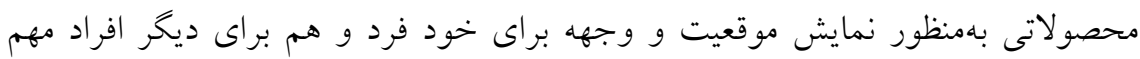

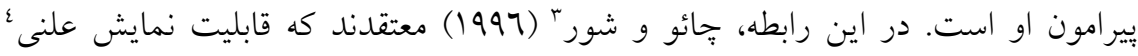
بعد مهمى از مصرف منزلتگرا است. اين نوع مصرف بيشتر مرتبط با خريد و استفاده از محصولاتى است كه مصرف علنى دارند (محصولاتى كه در معرض ديد ديخران است) نسبت به محصولاتى كه خصوصى هستند. همجنين بايد توجه داشت كه مصرف محصولات

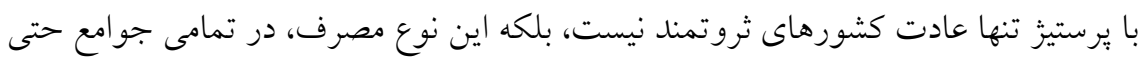

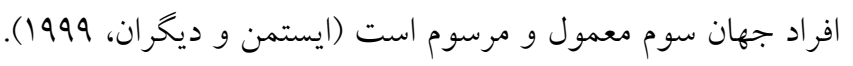

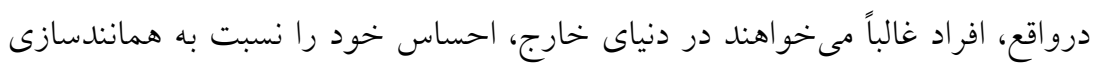

1. status consumption

3. Chao and Schor
2. Eastman

4. social visibility 
Relation of the Consumer Susceptibility to Interpersonal Influence and ...

با علائمى نشان دهند- جه كسى هستيم و نشان از جهه جيزى داريم - كه اين كار به شكل

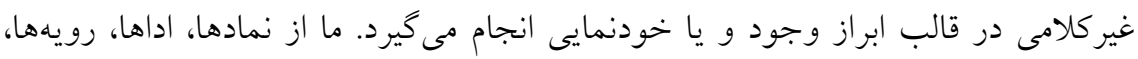

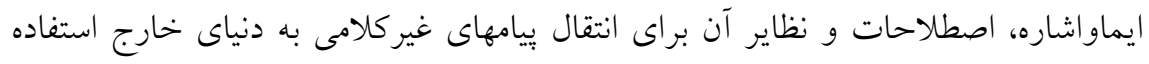

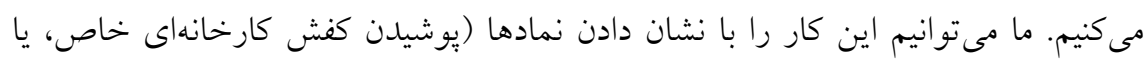

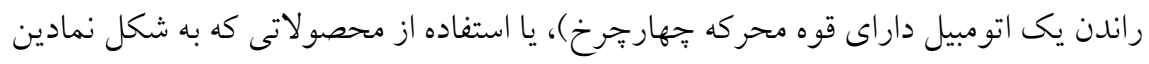

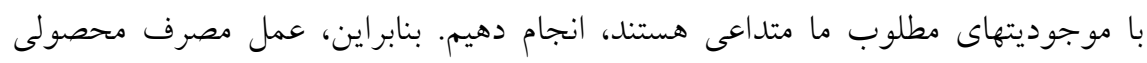

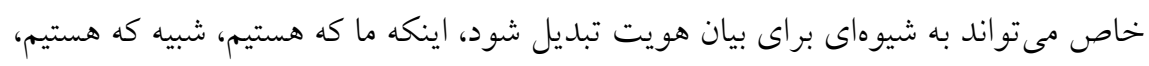

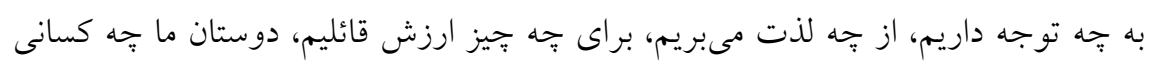

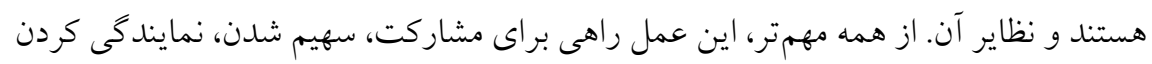

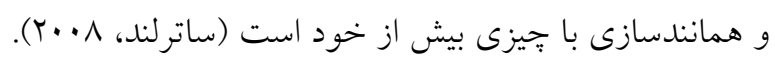

\section{ب) عوامل فردى و اجتماعى مؤثر بر مصرف منزلت}

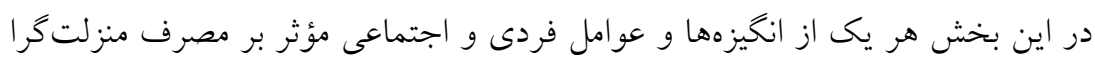
موردبحث قرار كرفته است.

\section{1- 1 مصرف بىتوجه به نقش}

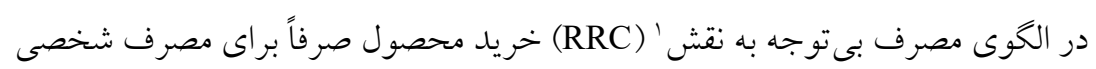

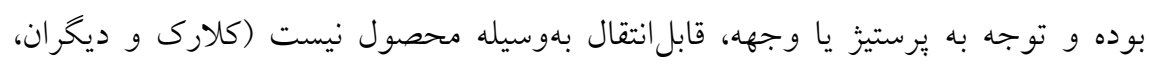

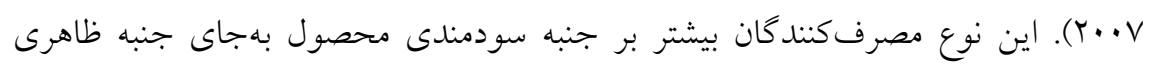

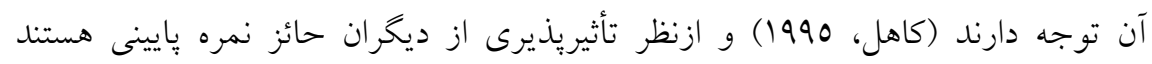

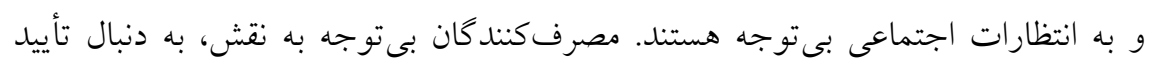

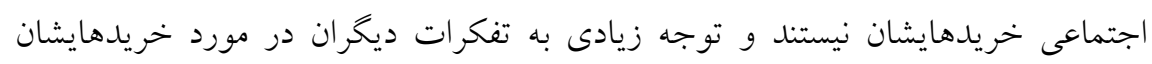

1. role-relaxed consumption 


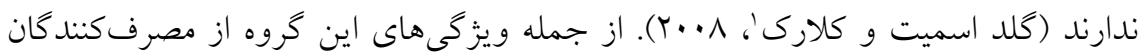
اين است كه داراى اعتمادبهنفس و عزتنفس بالا هستند، همخينين خود را بهعنوان فردى تحصيل كرده، مطلع، منطقى، معقول و باهوش مى دانند (كاهل'؛ 1990). درنهايت مى دوتوان

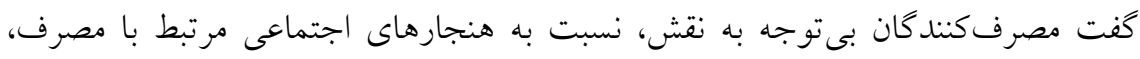

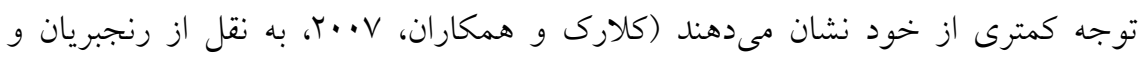

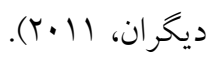

\section{r- r r تأثير بذيرى از نفوذ ديخران}

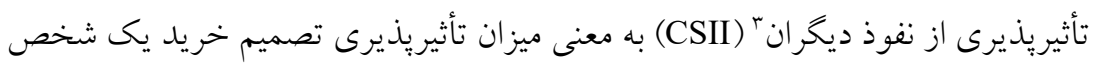

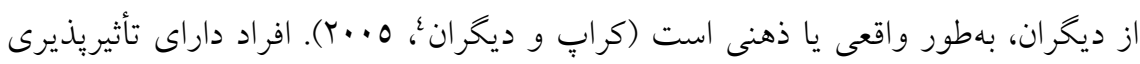

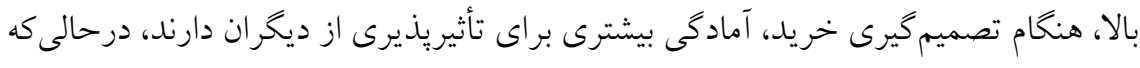

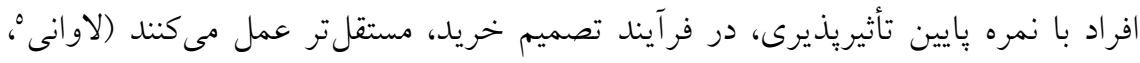

ميدان محيط اجتماعى" به اثرات مردم ديخر بر مصرفكننده در يك وضعيت مصرفى

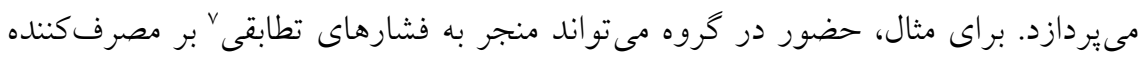

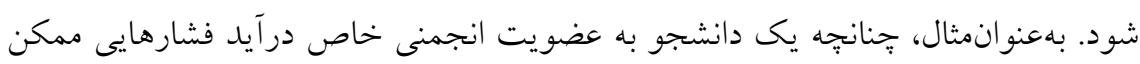

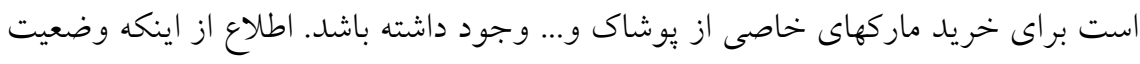

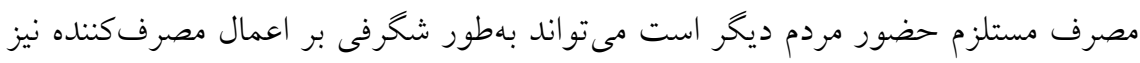

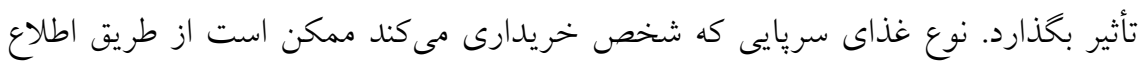

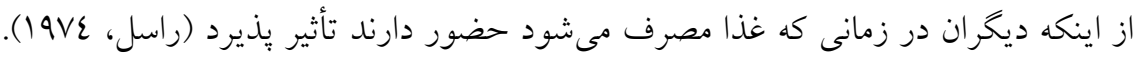

1. Goldsmith and Clark

3. consumer susceptibility to interpersonal influence

5. Lalwani

6. field of social surroundings
2. Kahle

4. Kropp

7. conformity pressures 
از ديدكاه خردهفرشى، ترغيب كردن ابعاد اجتماعى خريد هميشه سودمند است. وقتى كه

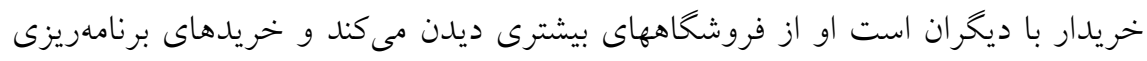

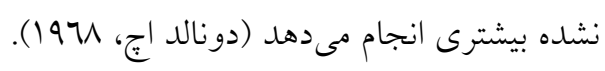

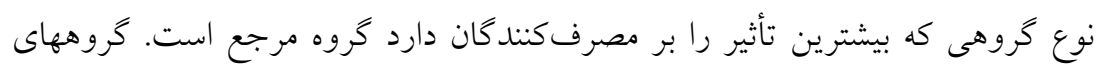

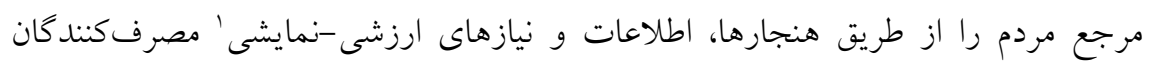

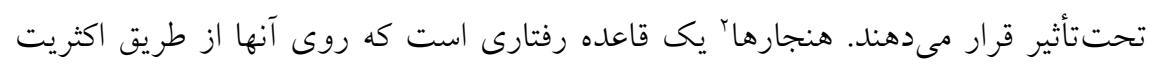

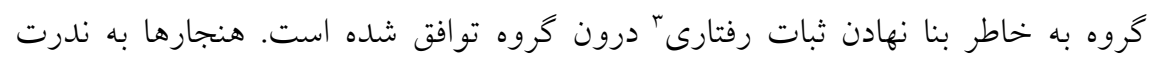

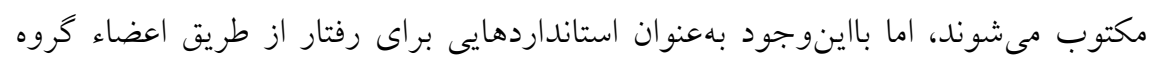

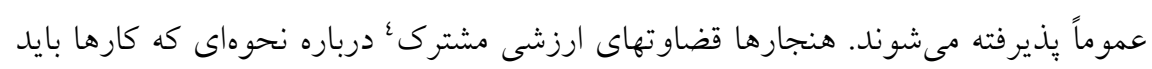
توسط اعضاى كروه انجام شوند را بيان مى كنند.

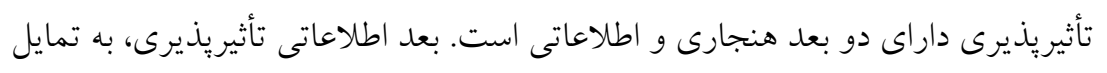

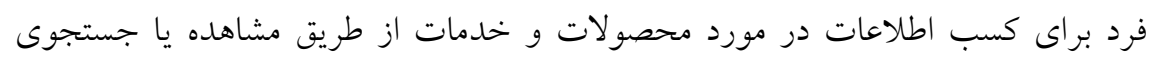

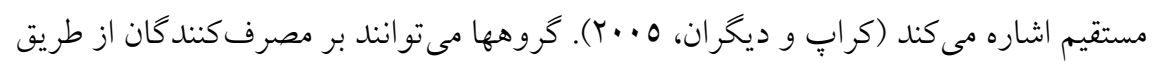

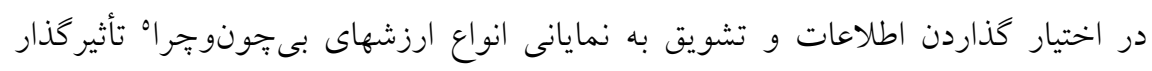

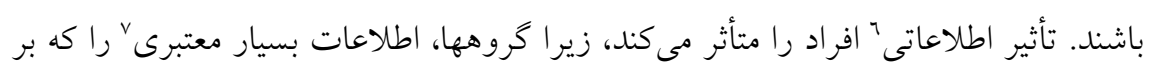

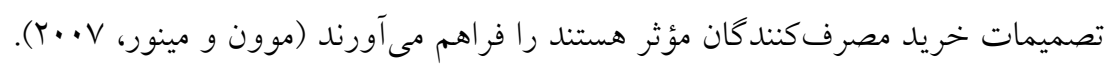

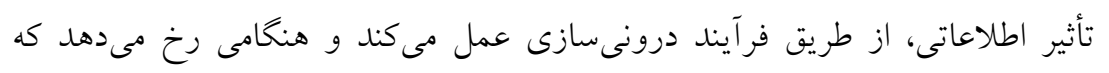

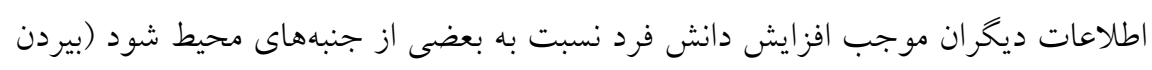

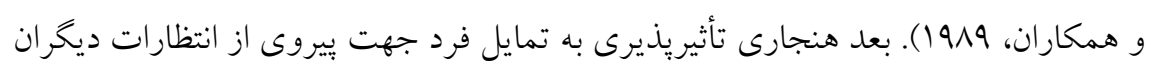

$\begin{array}{ll}\text { 1. value-expressive needs } 2 \text {. norms } & \end{array}$

4. shared value judgements 5. certain types of values

7. highly credible information
3. behavioral consistency

6. informational influence 
اشاره دارد (برن كرانت و كازينو'، 19V0). هنگامى كه هنجارها جهت تأثير بر رفتار عمل

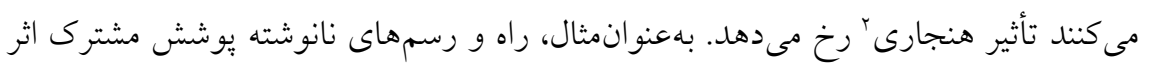

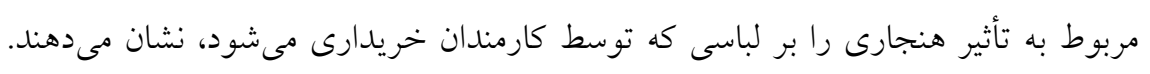

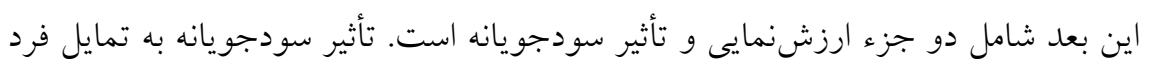

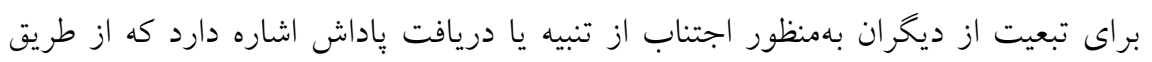
فرايند بييروى عمل مى كند (بيردن و همكاران، 1919).

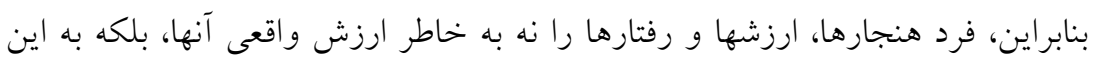

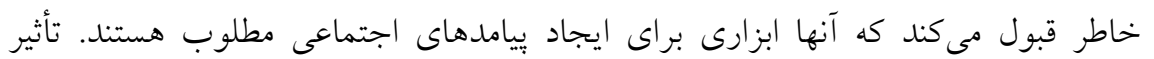

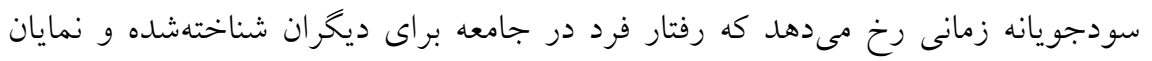

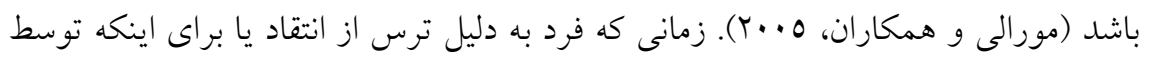

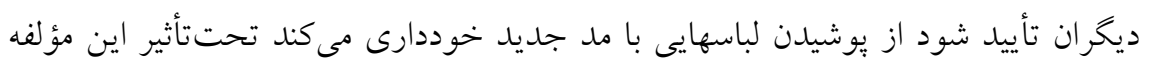

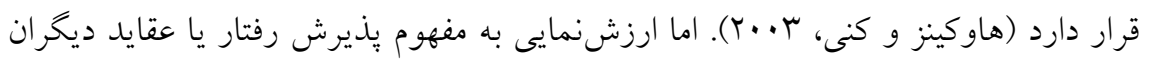

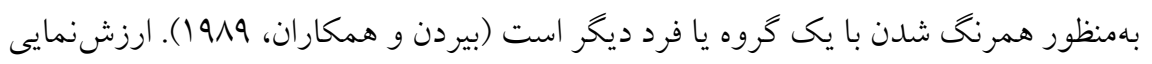

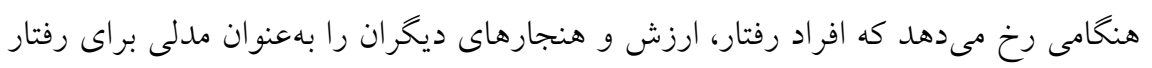

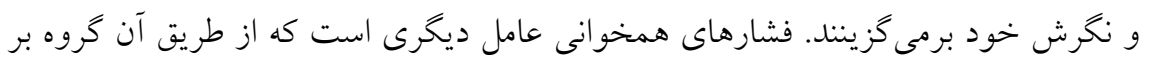

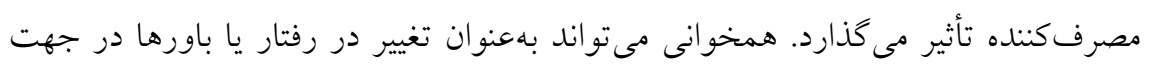

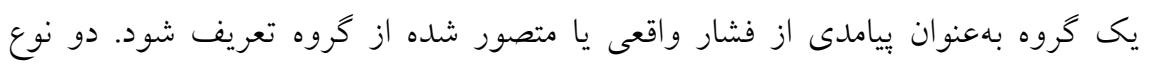

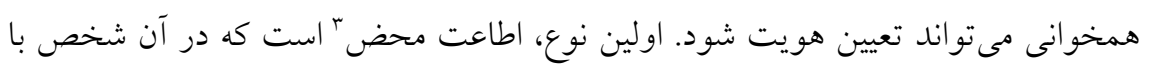

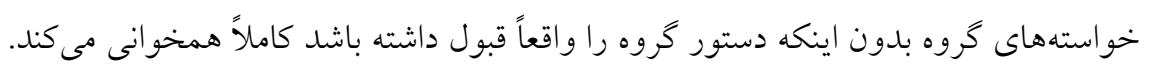

1. Burkart and Cousineau

2. normative influence

3. simple compliance 


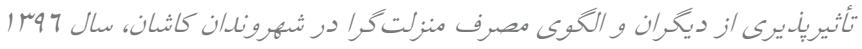

Relation of the Consumer Susceptibility to Interpersonal Influence and ...

نوع دوم اعتقاد نهانى' است كه در آن شخص باورهاى خودش را در جهت گروه بهراستى تغيير مى دهد (مون و مينور، V... (Y).

\section{r- تشخص يذيرى (تمايل به منحصربهفرد بودن)}

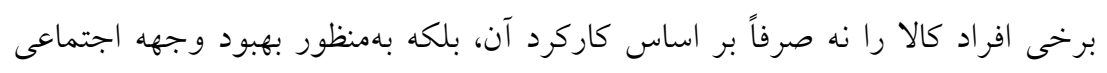

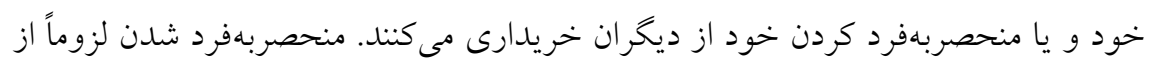

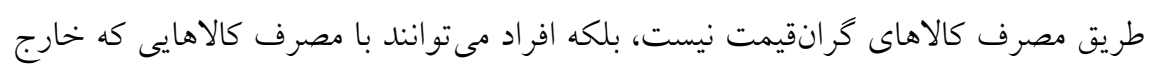

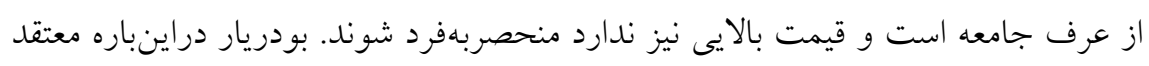

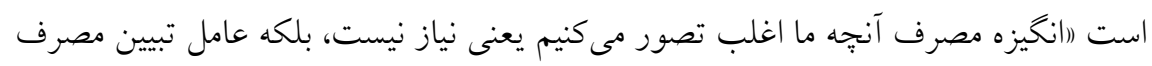

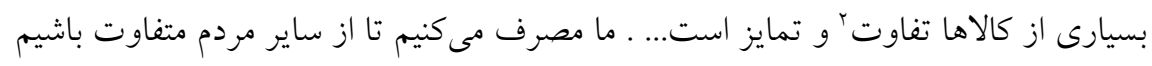

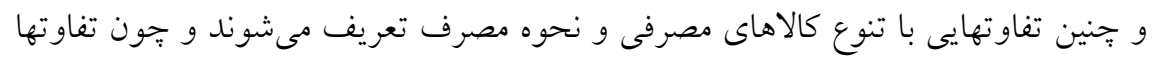

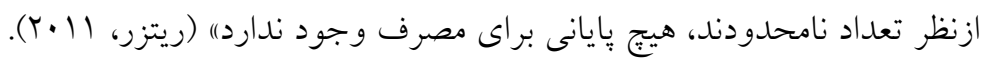

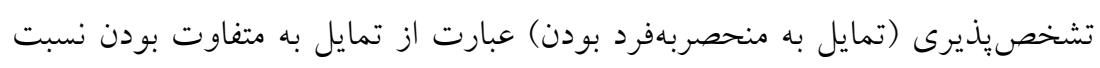

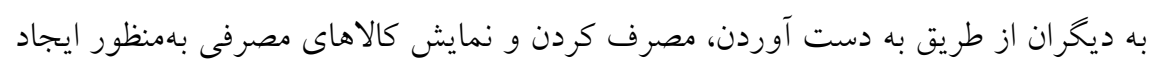
و بالا بردن تصوير اجتماعى و شخصى فرد است. متفاوت بودن نسبت به ديخران يا متمايز

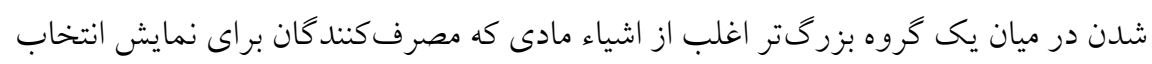

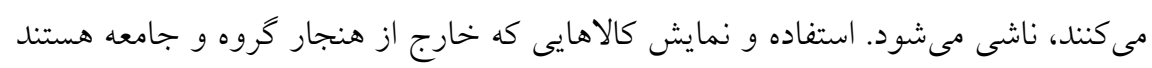

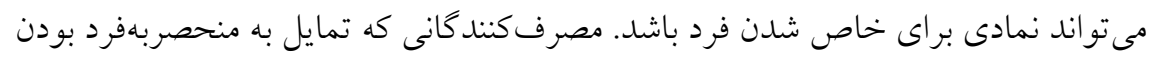

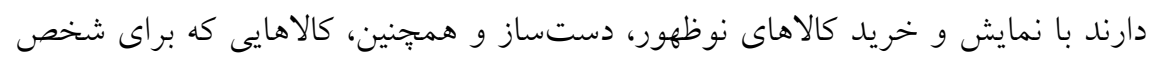

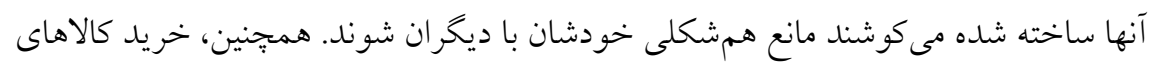

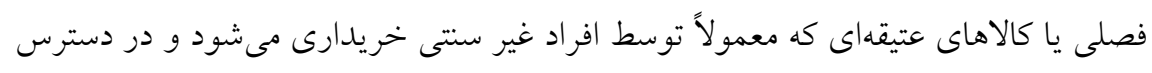

1. private acceptance

2. difference 
توده مردم نيست مى تو اند در منحصربه فرد بودن به افراد كمك كند (تيان و ديكران، (Y.C).

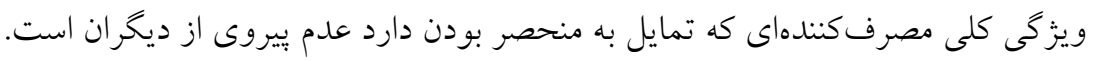

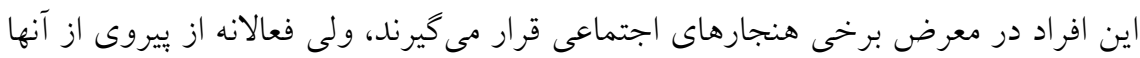

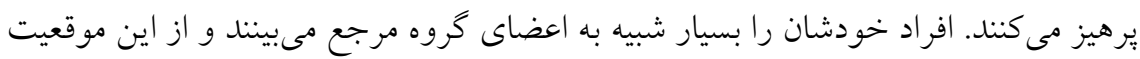

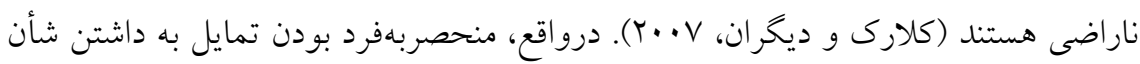
و منزلت متفاوت است (لاتر و ديخران، · • (Y).

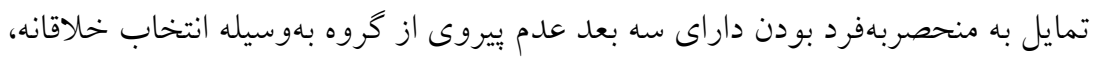

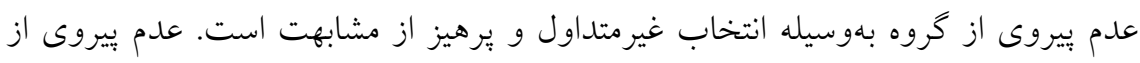

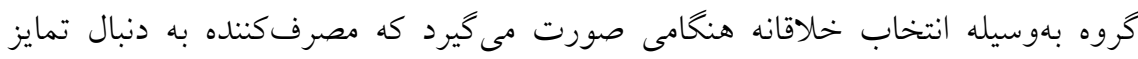

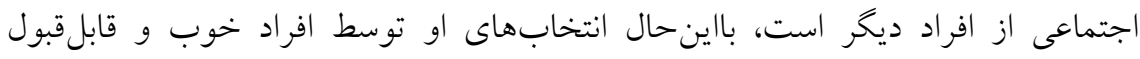

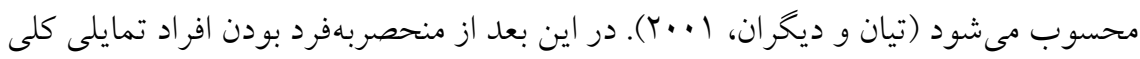
براى انتخاب كالاها و برندهايى دارند كه بهطور كامل با هنجارهاى مصرف كننده گروه مرجع

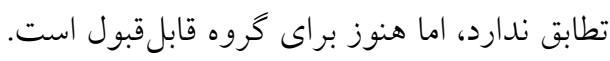

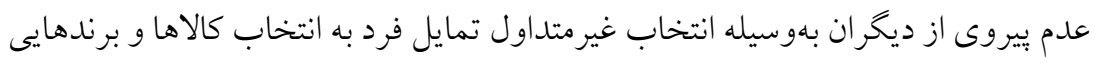

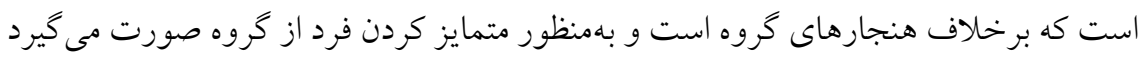

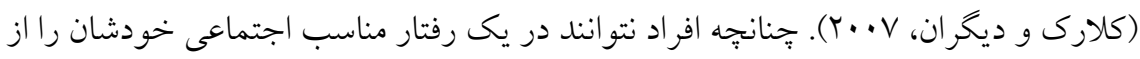

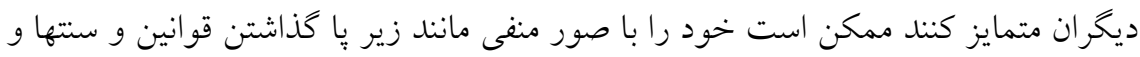

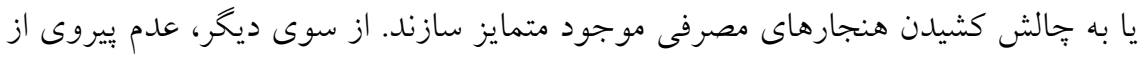

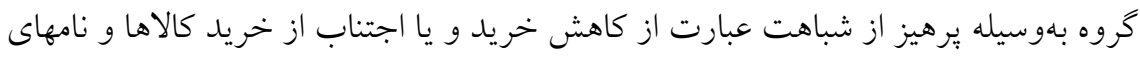

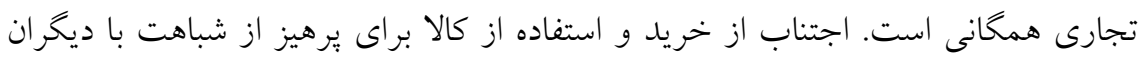

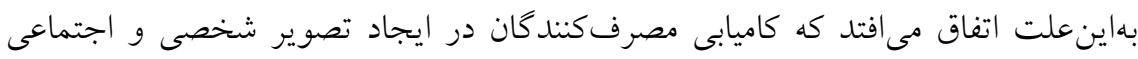

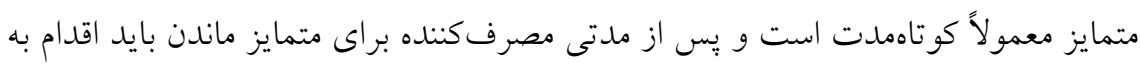


Relation of the Consumer Susceptibility to Interpersonal Influence and ...

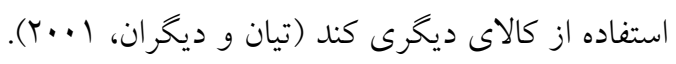

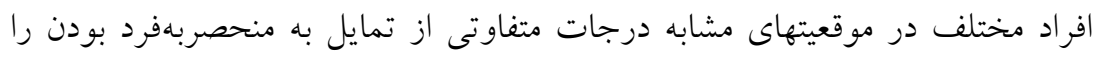

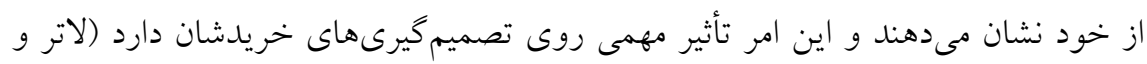

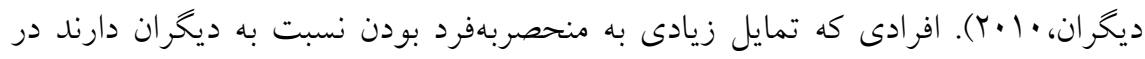

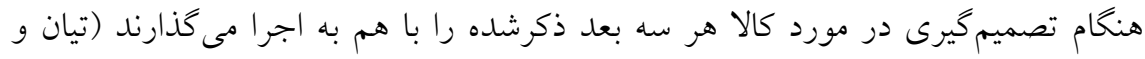

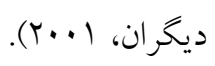

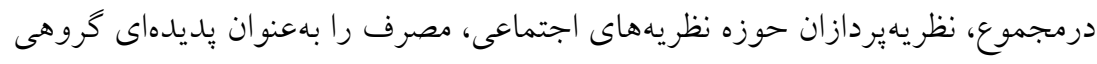
يا نوعى رفتار جمعى كه به شكل گيرى گروهها و عضويت فردى كمكى مى كند، تلقى مى كنند.

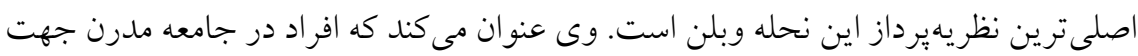
نمايش موقعيت اجتماعى خويش مصرف مى كنند.

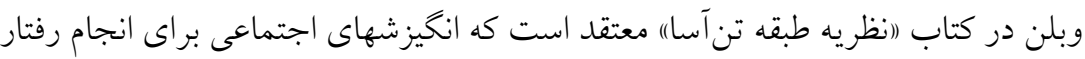
رقابتآميز، بنيان تبيين بديده مصرف مدرن است: (امصرف نمايان كالاهاى ارزشمند وسيلهاى

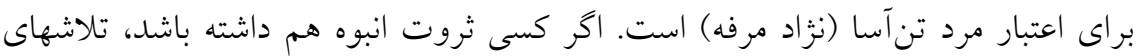

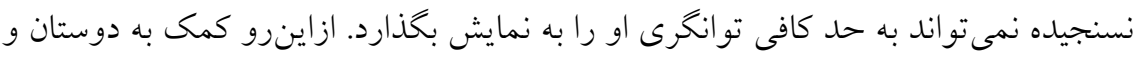

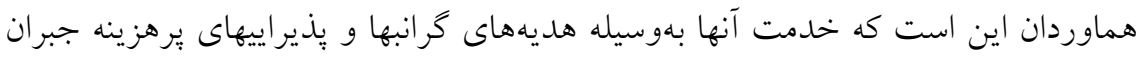

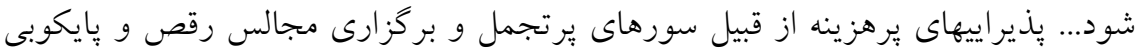

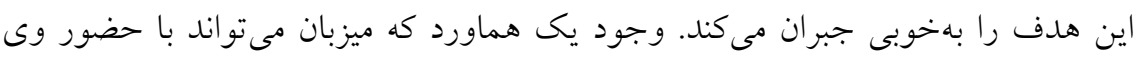

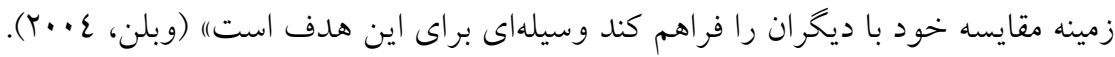

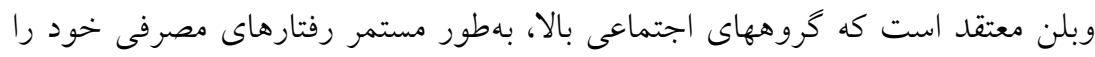

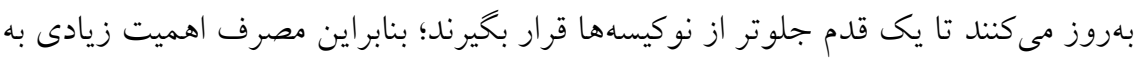

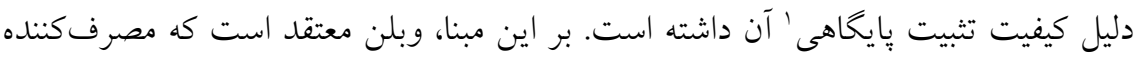


براى كسب تشخص، احترام و منزلت اجتماعى مصرف مى كند و اين كار از دو طريق فراغت نمايشى و مصرف نمايشى صورت مى يذيرد. فراغت نمايشى يكى از راههاى مؤثر نشان دادن

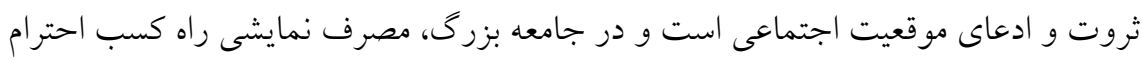

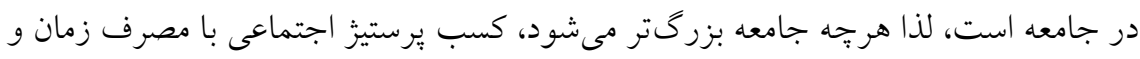
نشان دادن غيرمولد كمتر مى شود (دكينز، 1999)

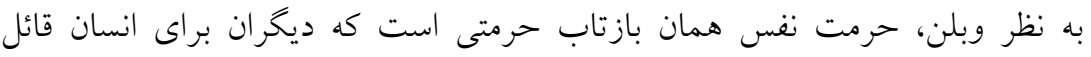

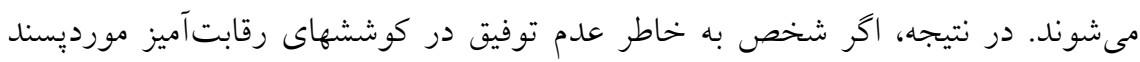

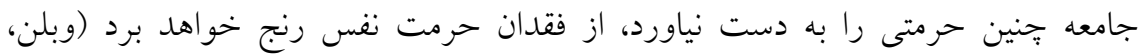

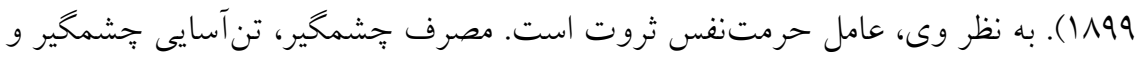

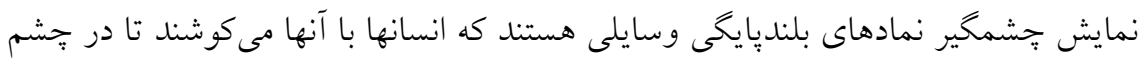

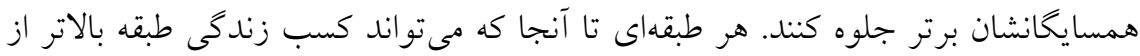

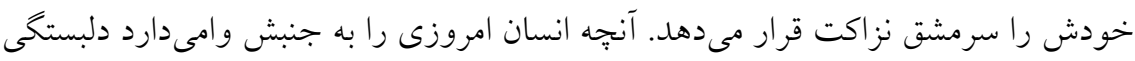

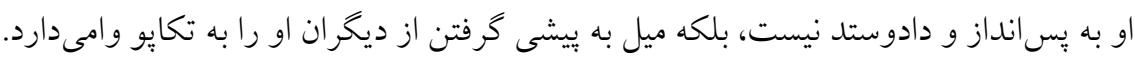

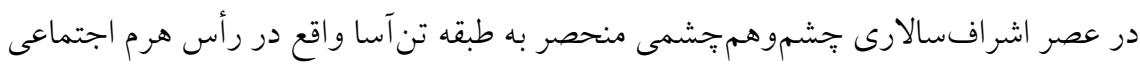

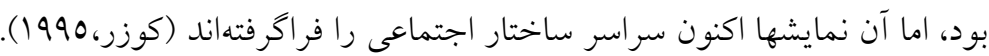

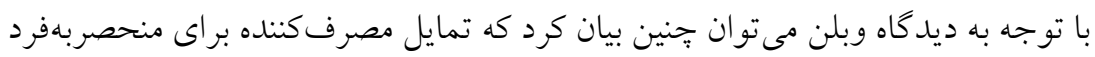
بودن موجب مىشود افراد از ييروى بعضى هنجارهاى اجتماعى اجتناب كنند (كلارك و

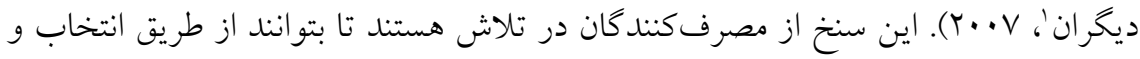

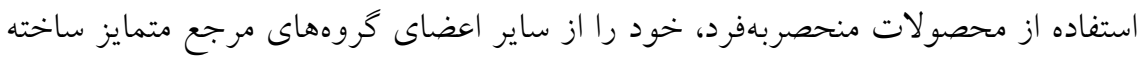

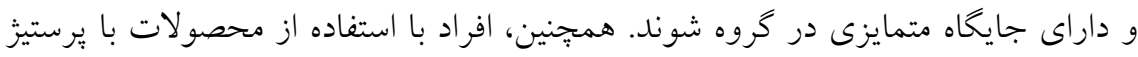

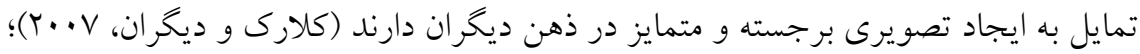

1. Clarke. 
Relation of the Consumer Susceptibility to Interpersonal Influence and ...

لذا مىتوان انتظار داشت كه تمايل به منحصربهفرد بودن تأثير مثبى بر مصرف منزلتگرا داشته باشد.

از سوى ديخر، در مصرف بىتوجه به نقش، فرد توجه كمترى بر عقايد و نظرات ديخران

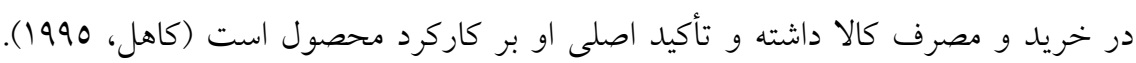

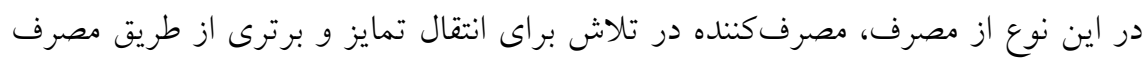

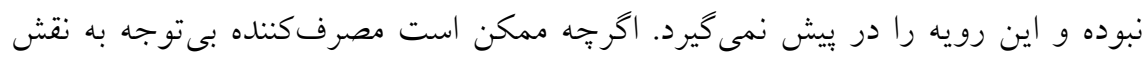

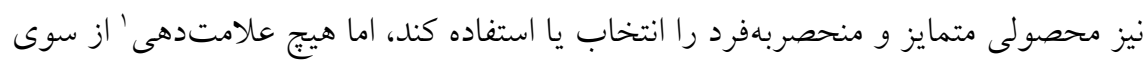

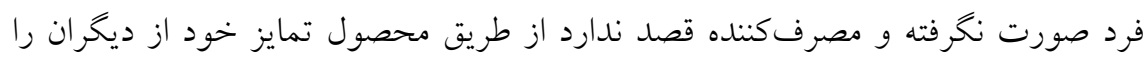
نشان دهد.

مصرف بىتوجه به نقش رابطه معكوسى با تأثيريذيرى از ديخران دارد. درواقع

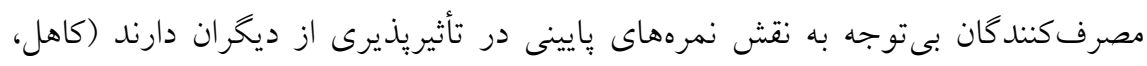

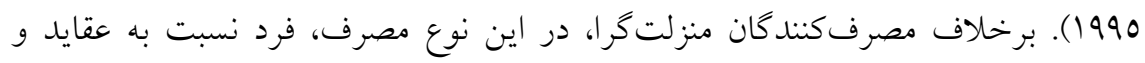

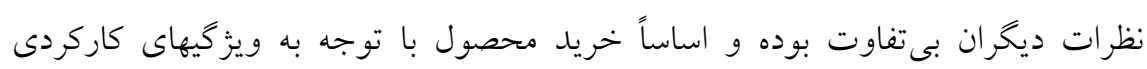

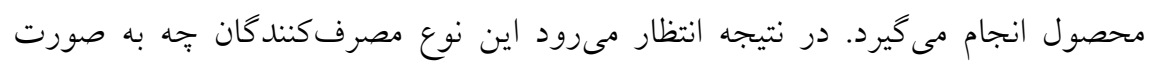
هنجارى يا اطلاعاتى تحت تأثير ديخران نباشند.

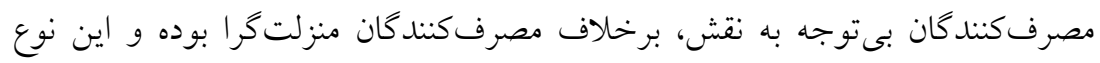

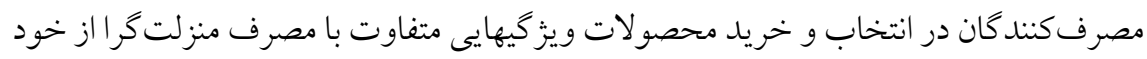

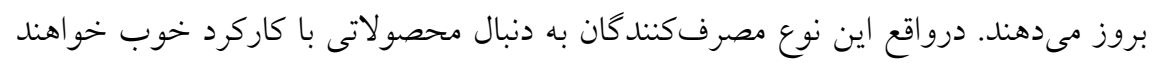

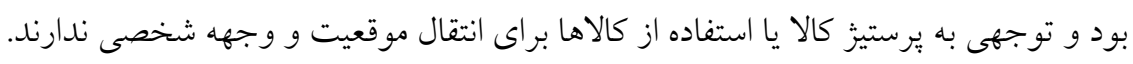

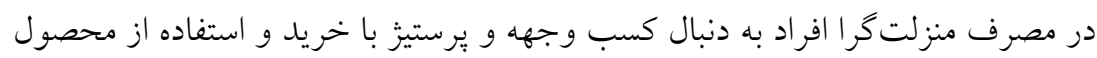

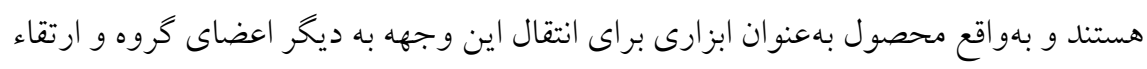
1. signaling 
تصوير اجتماعى خود نزد سايرين هستند. تأثيريذيرى فرد به صورت اطلاعاتى يا هنجارى

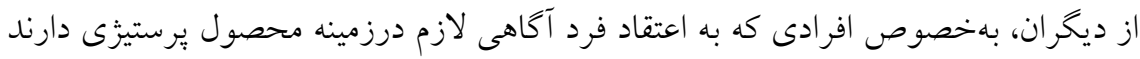

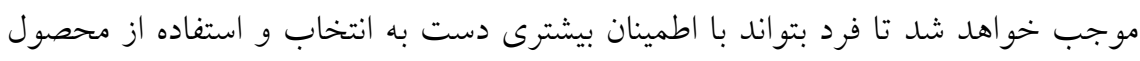

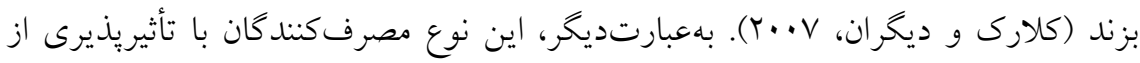

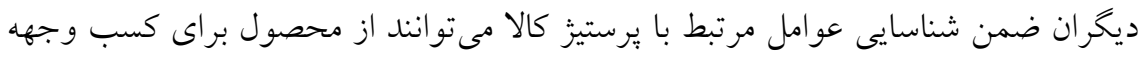

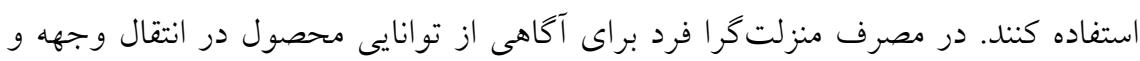
يرستيز توجه زيادى به واكنشهاى سايرين دارد تا بتو اند سرنخهايى درزمينه انتخاب درست برست

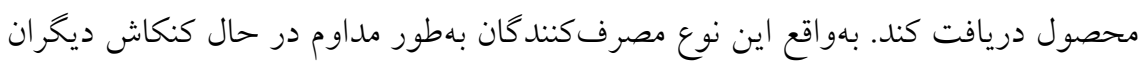

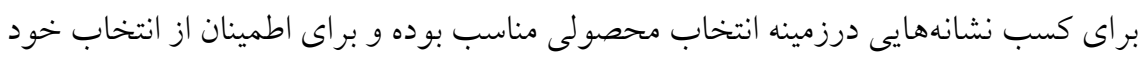

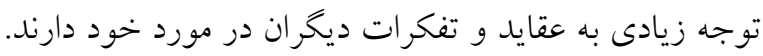

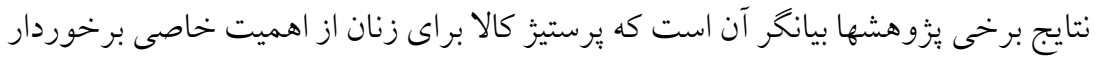

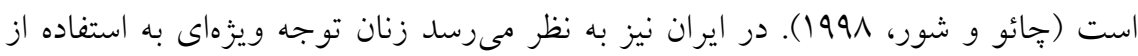

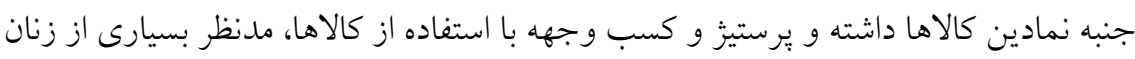
ايرانى است (رنجبريان و همكاران، 11 (Y). درزمينه مصرف منزلت كرا، شاخص تمايل به منحصر بهفرد بودن از جمله عوامل فردى مؤثر

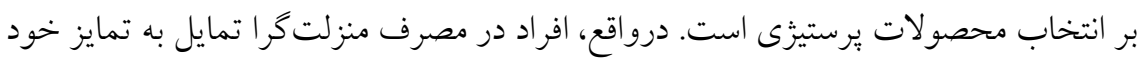
از ديخر ان داشته و سعى مى كنند تا كالاهايى را انتخاب كنند كه آنها را در اين امر كمك كندي. 
Relation of the Consumer Susceptibility to Interpersonal Influence and ...

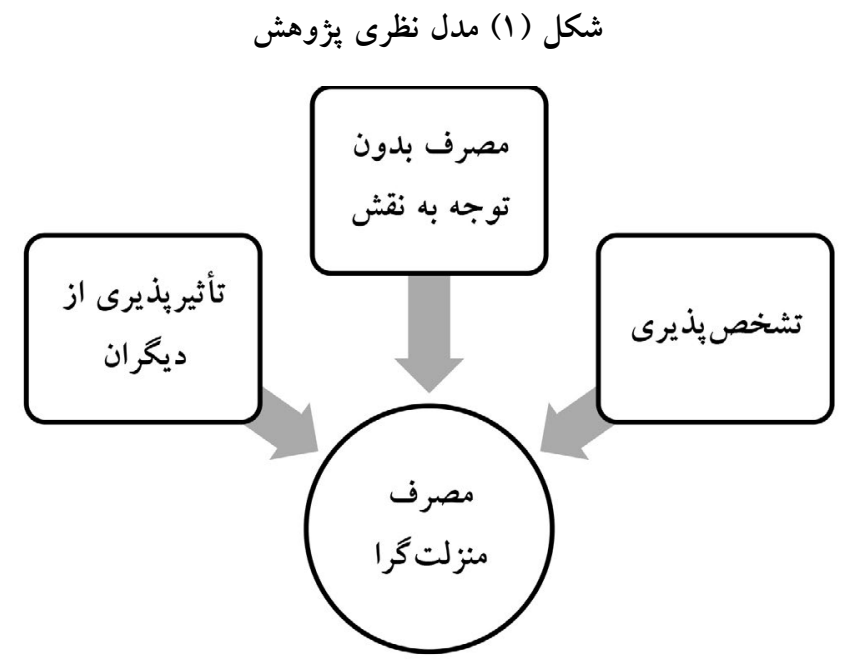

با توجه به مباحث فوق، در اين تحقيق فرضيههاى يزوهش مبنى بر ارتباط بين هر يك

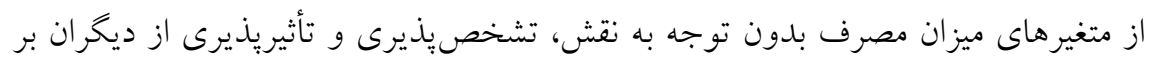
ميزان مصرف منزلت گرا تدوين و موردبررسى قرار گرفته است.

روش

اين مطالعه از نوع بيمايش اجتماعى بوده و اطلاعات تحقيق با استفاده از تكنيك

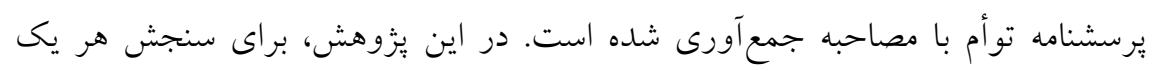
از متغيرهاى اصلى يزٔوهش از كويههاى مربوط در قالب طيف ليكرت استفاده شده است.

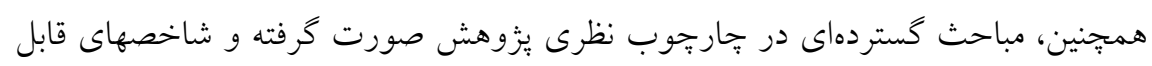
اجماع و قابل اشتراكى در مورد آنها آورده شده است كه اعتبار سازهاى مفاهيم، مؤلفهها و

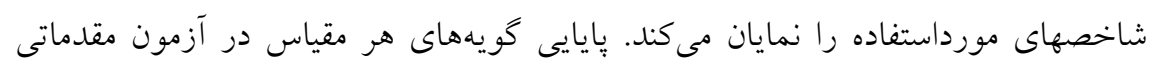

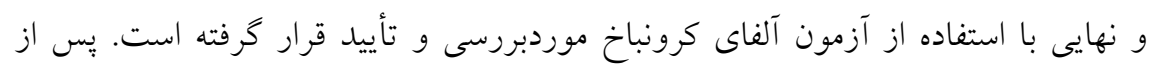


جمع آورى دادههاى تحقيق، با استفاده از برنامه كامييوترى SPSS و فعاليتهاى آمارى مربوطه، تجزيهوتحليل يافتهاى تحقيق صورت گرفته است.

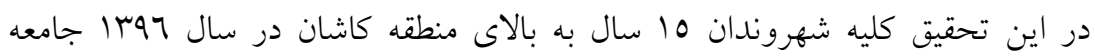
آمارى تحقيق را تشكيل مىدهند. ميزان حجم نمونه بر اساس فرمول نمونه كيرى كوكران و

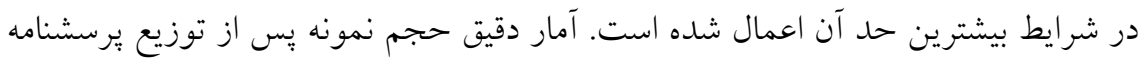

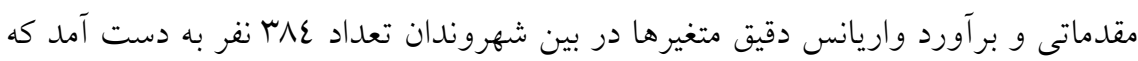
0.7 نقر تعيين شده است.

در اين تحقيق، متغيرهاى مصرف بدون توجه به نقش، تشخصيذيرى و تأثيريذيرى از

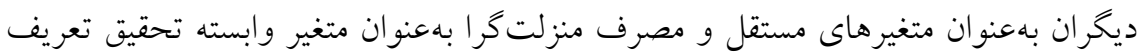

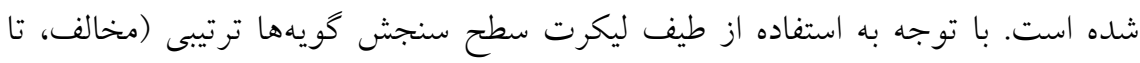

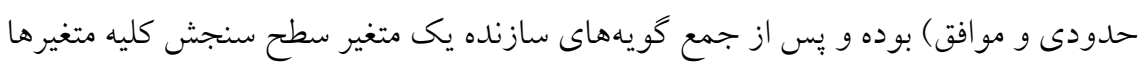
به سطح فاصلهاى تبديل شده است.

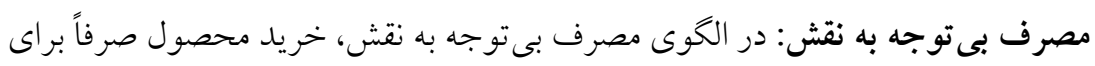

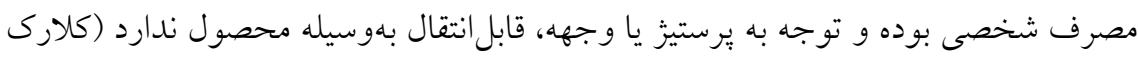

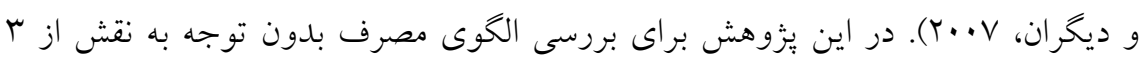

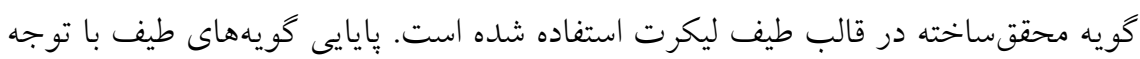

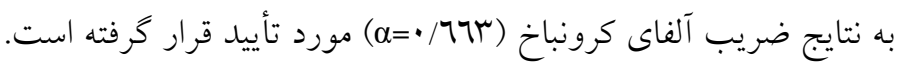

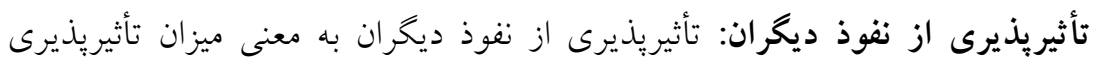

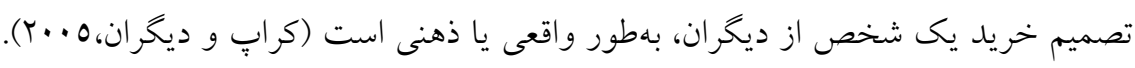

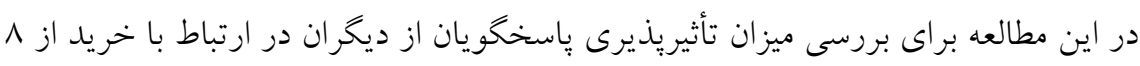

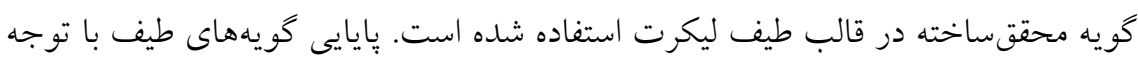

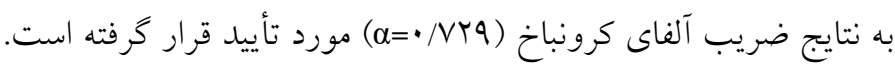


Relation of the Consumer Susceptibility to Interpersonal Influence and ...

تشخص يذيرى: تشخصيذيرى به معناى نمايش برترى خود به ديخران (وارستهفر و

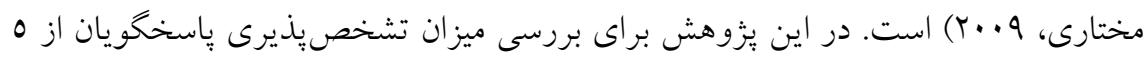

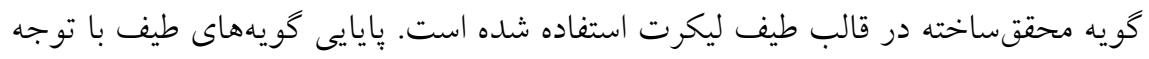

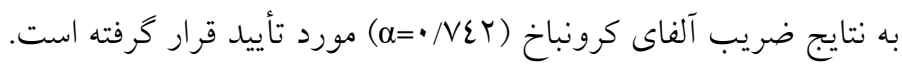

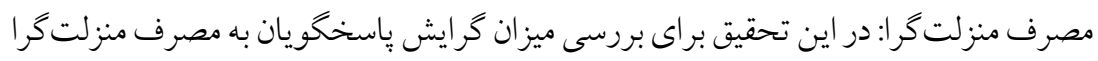

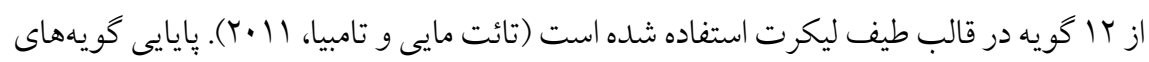

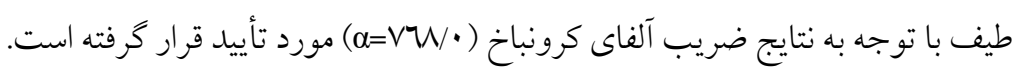

\section{يافتهها}

در اين بخش، ابتدا متغيرهاى مستقل و وابسته تحقيق توصيف شده و بسازآن به تبيين

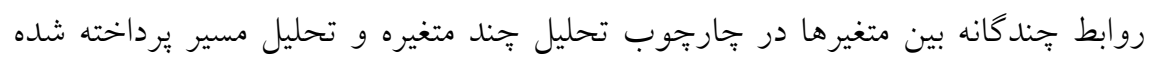

$$
\text { - } 1
$$

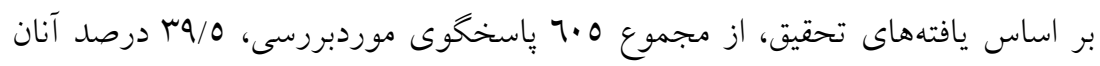

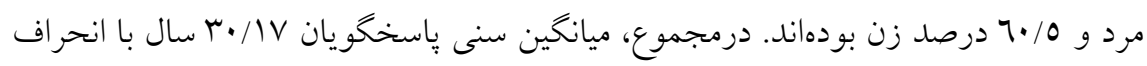

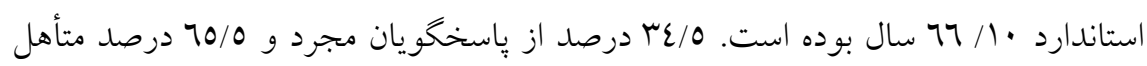

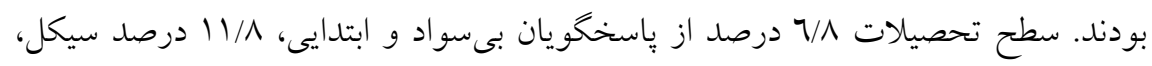

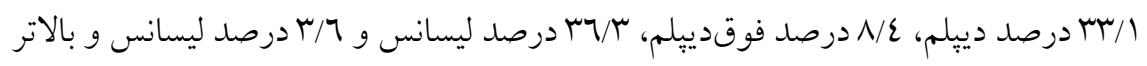

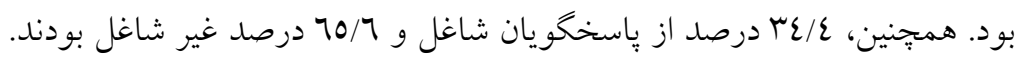




\section{r- ب توصيف متغيرهاى اصلى}

در اين مطالعه متغيرهاى مصرف بدون توجه به نقش، تأثيريذيرى از نفوذ ديكران

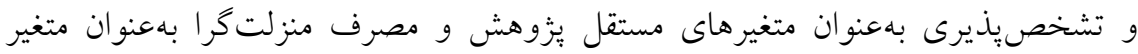

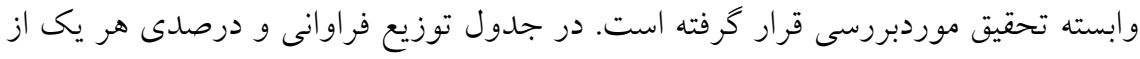
متغيرهاى فوق ارائه شده است.

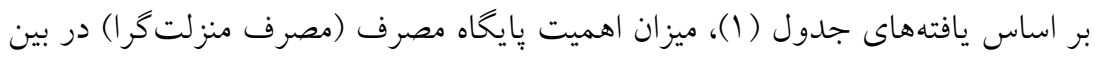

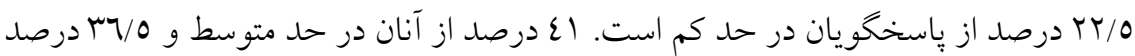

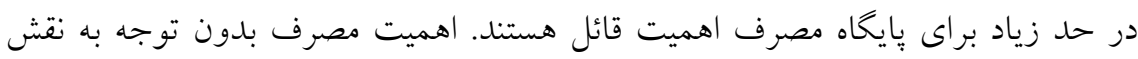

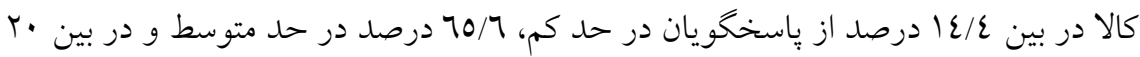
درصد از آنان از اهميت زياد برخوردار است. جدول (1) توزيع فراوانى و درصدى متغيرهاى وابسته و مستقل تحقيق

\begin{tabular}{|c|c|c|c|c|c|c|c|}
\hline$\%$ & f & طبقات & متغيرها & $\%$ & f & طبقات & متغيرها \\
\hline $1 \varepsilon / \varepsilon$ & $\Lambda V$ & كم & \multirow{4}{*}{ مصرف بى توجه به } & $T Y / O$ & רזו & كم & \multirow{4}{*}{ مصرف منزلت گرا } \\
\hline $70 / 7$ & rqv & متوسط & & $\varepsilon$ & rE^ & متوسط & \\
\hline r. & $|r|$ & زياد & & $\mathrm{rr} / \mathrm{o}$ & rrI & زياد & \\
\hline $1 \ldots$ & 7.0 & جمع & & $1 \ldots$ & 7.0 & جمع & \\
\hline$r \varepsilon / \varepsilon$ & $r \cdot \Lambda$ & كم - لم & \multirow{4}{*}{ تأثير يذيرى از ديخران } & $r v / \varepsilon$ & TrT & كم & \multirow{4}{*}{ تشخص يذيرى } \\
\hline$\varepsilon 0 / r$ & $r V \varepsilon$ & متوسط & & $\mathrm{rV} / \mathrm{o}$ & TrV & متوسط & \\
\hline$r \cdot / r$ & r & زياد & & ro/l & lor & زياد & \\
\hline $1 \ldots$ & 7.0 & جمع & & $1 .$. & 7.0 & جمع & \\
\hline
\end{tabular}


Relation of the Consumer Susceptibility to Interpersonal Influence and ...

علاوه بر اين، يافتههاى جدول فوق بيانخر اين امر است كه ميزان تشخصيذيرى در بين

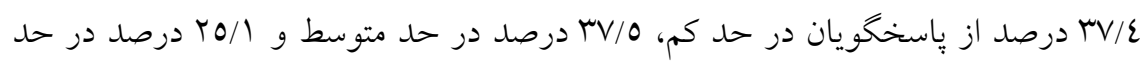

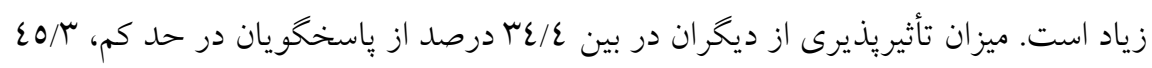
درصد در حد متوسط و ب/ •r درصد در حد زياد است.

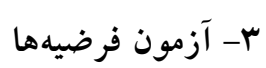

در جداول (Y)، (r) و (ع) روابط بين هر يك از متغيرهاى مصرف بدون توجه به نقش، تأثيريذيرى از ديخران و تشخصيذيرى با متغير وابسته يزوهش يعنى مصرف منزلت در قالب جداول دوبعدى موردبررسى قرار كرفته است. همجنين، جهت آزمون فرضيههاى يززوهش از ضريب همبستخى و درنهايت تحليل مسير استفاده شده است.

\section{بررسى رابطه بين مصرف بىتوجه به نقش و مصرف منزلت} در جدول (Y) رابطه بين مصرف بدون توجه به نقش با متغير وابسته يزوهش يعنى مصرف منزلت گرا موردبررسى قرار خرفته است. جدول (Y) رابطه بين مصرف بدون نقش و مصرف منزلت

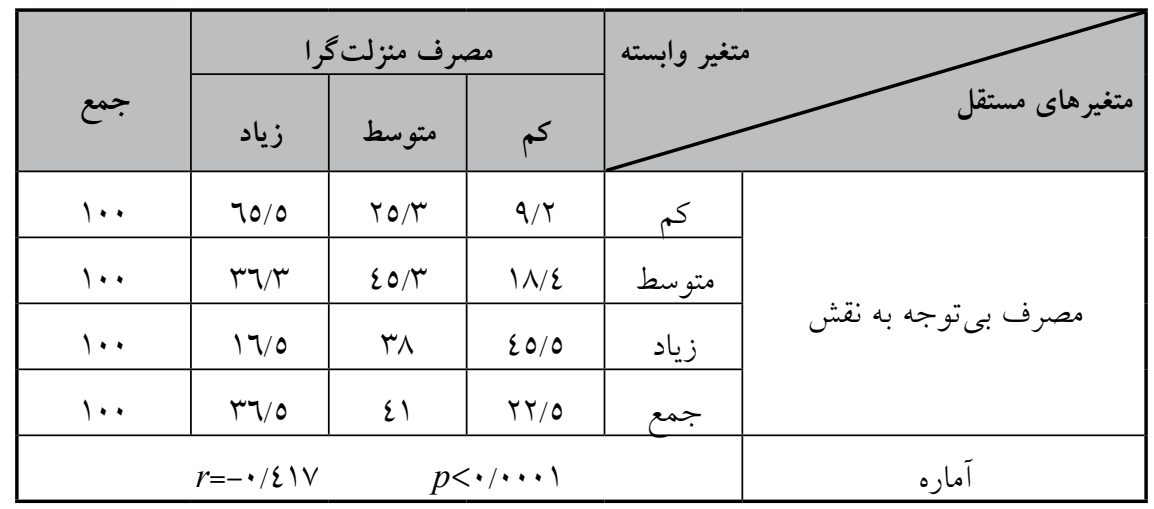


يافتهاى جلدول نشان مىدهند ميزان مصرف منزلتخرا در حد زياد در بين افراد با ميزان مصرف بدون توجه به نقش در كم، متوسط و زياد به ترتيب / 9/r، T/ T و 70/0 درصد بوده و

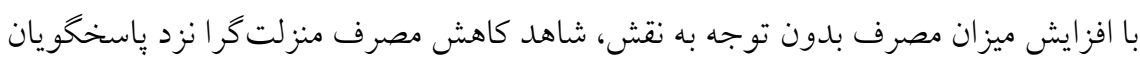

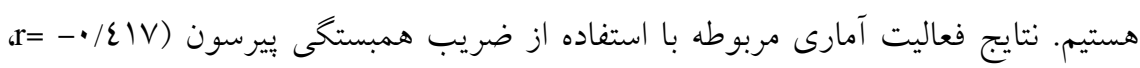

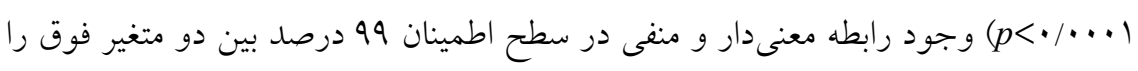
نشان مى مهد.

\section{بررسى رابطه بين تشخصيذيرى و مصرف منزلت}

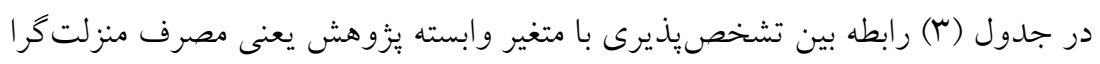
موردبررسى قرار كرفته است.

جدول (r) رابطه بين تشخص بذيرى و مصرف منزلتگرا

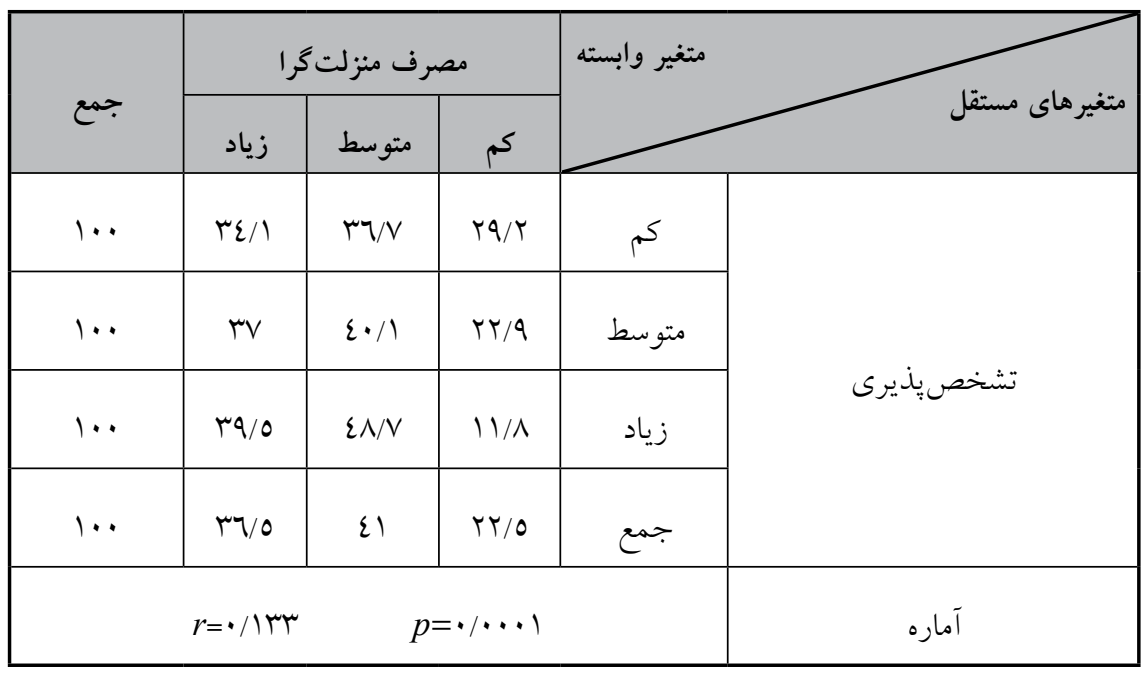


Relation of the Consumer Susceptibility to Interpersonal Influence and ...

در بررسى رابطه بين ميزان تشخصيذيرى و مصرف منزلتگرا، يافتهاى يزوهش بيانخر اين امر است كه با افزايش ميزان تشخصيذيرى، ميزان منزلت گرايى در مصرف نيز افزايش يافته است، بهكونهاى كه مصرف منزلت گرا در حد زياد در بين ياسخخويان با ميزان تشخص يذيرى در حد كم /عـ درصد بوده است كه اين ميزان در بين باسخخويان با ميزان تشخصيذيرى در حد زياد به ه/0 درصد افزايش يافته است. نتايج ضريب همبستخى

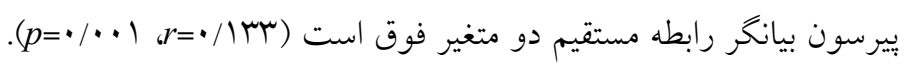

\section{بررسى رابطه بين تأثيريذيرى از ديخران و مصرف منزلت گرا} در جدول (ع) رابطه بين تأثيريذيرى از ديخران با متغير وابسته يزوهش يعنى مصرف منزلت كرا موردبررسى قرار كرفته است.

جدول (ع) رابطه بين تأثير بذيرى از ديخران و مصرف منزلت

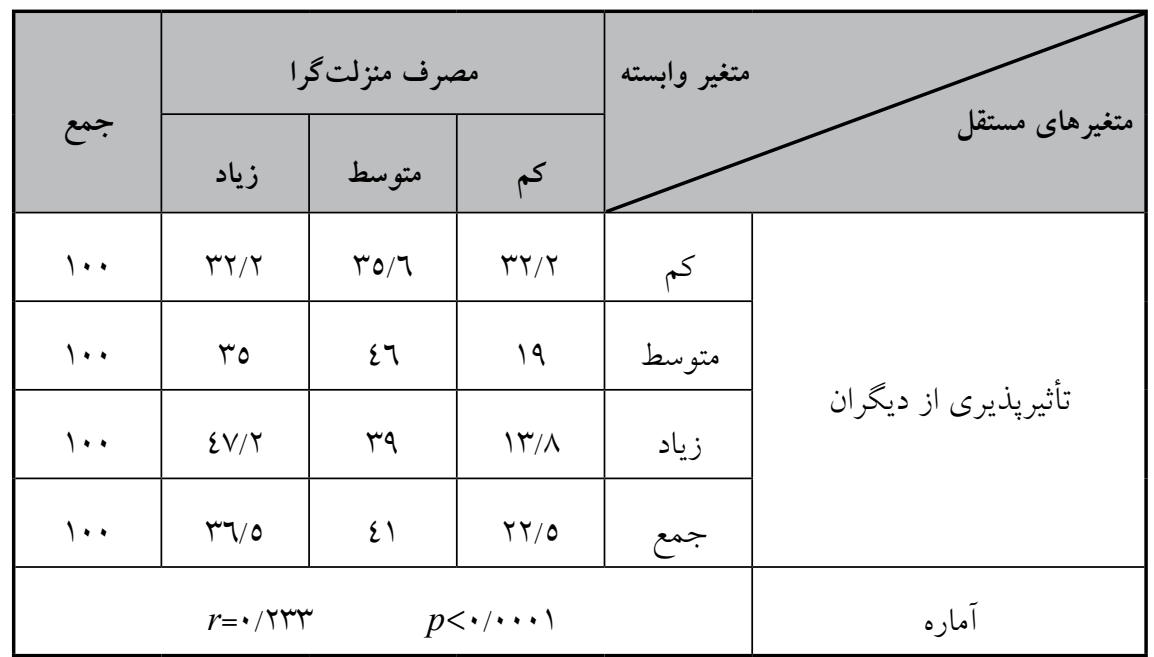


بر اساس يافتهاى جدول فوق با افزايش ميزان تأثيريذيرى پاسخخويان از ديخران، بر

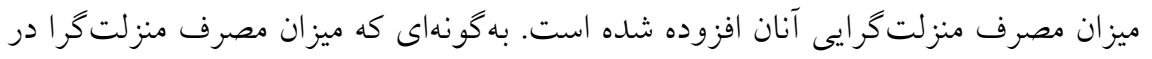

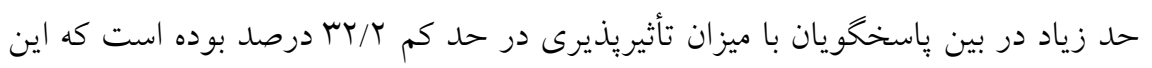

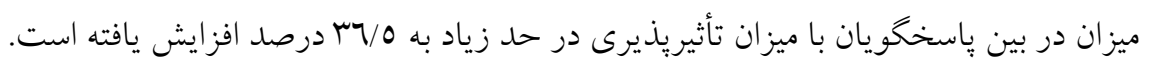

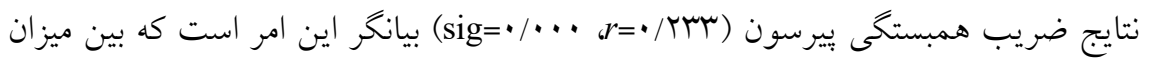

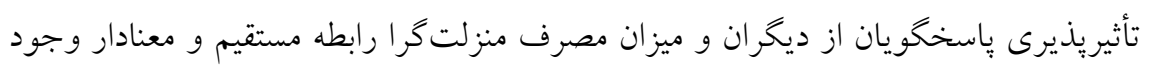

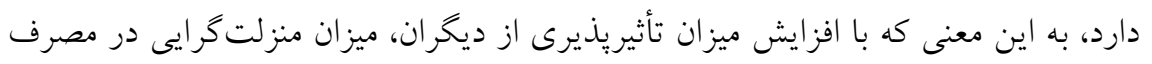

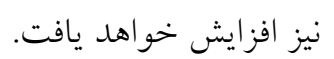

تحليل جندمتغيره

در اين بخش براى نشان دادن اثرات مستقيم و غيرمستقيم متغيرهاى مستقل بر متغير

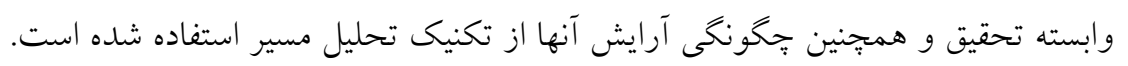

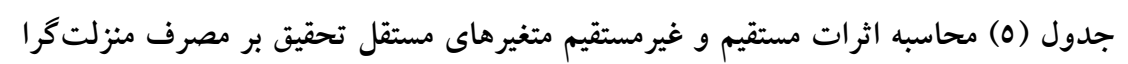

\begin{tabular}{|c|c|c|c|}
\hline \multirow{2}{*}{ كل } & \multicolumn{2}{|c|}{ ضرايب اثر } & \multirow{2}{*}{ 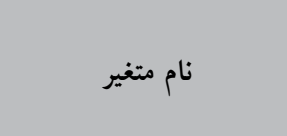 } \\
\hline & اثر غيرمستقيم & اثر مستقيم & \\
\hline$-\cdot / \mu$ & - & $-\cdot / \mu \Lambda$ & مصرف بىتوجه به نقش \\
\hline • &.$/ 11 \varepsilon$ &.$/ 11 \mathrm{~V}$ & تأثيريذيرى از ديكران \\
\hline$\cdot / \wedge r$ & - & $\cdot / \wedge r$ & تشخصيذيرى \\
\hline
\end{tabular}


Relation of the Consumer Susceptibility to Interpersonal Influence and ...

جدول (0) نشان مىدهد كه كليه متغيرها را مىتوان به لحاظ اثر كذارى كل به دو قسمت اثر گذارى منفى و اثر گذارى مثبت تقسيم كرد. از طرف ديخر هر قسم از انواع فوق، اثر مستقيم و غيرمستقيم بر متغير وابسته دارند. در اثركذارى كل مثبت، متغير تأثيريذيرى از ديخران داراى بيشترين اثر بر مصرف منزلتگرا است ( اسب/•)، بهطورىكه اين متغير داراى 11/ اثر مستقيم و 1// • اثر غيرمستقيم است. در راستاى تحليل متغير فوق مىتوان كفت كه هر جهه ميزان تأثيريذيرى ياسخخويان از ديخران بيشتر شود، بر ميزان منزلت كرايى آنان در مصرف افزوده خواهد شد. تشخص يذيرى يا تمايل به منحصربهفرد بودن نيز با م••/ تأثير گذارى مثبت در مرتبه دوم قرار گرفته است. در ميزان اثر گذارى كل منفى، متغير مصرف

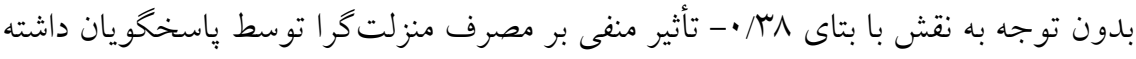
است. در ارتباط با تحليل متغير فوق نيز مىتوان گفت مصرف كالا براى اين گونه ياسخخويان صرفاً جنبه كاركردى داشته و توجهى به يرستيز آن ندارند. مقدار R بهدستآمده به روش همزمان بر اى متغير هاى فوق بر ابر 190 / • است. بهعبارتديخر، 19 درصد از مجموع تغييرات متغير وابسته توسط مدل تحليلى فوق تبيين مىشود. شكل (Y) دياگُ ام مسير عوامل مؤثر بر مصرف منزلتخرا

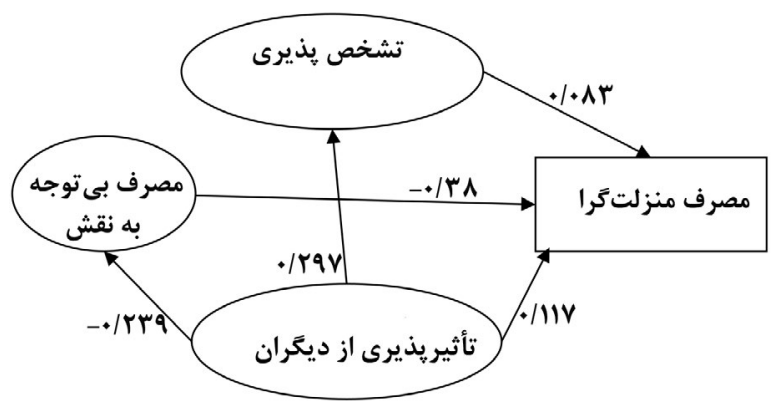


Social Welfare Quarterly, Vol 19, Summer 2019, No 73

\section{بحث:}

اين يزوهش با هدف شناسايى الخوى مصرف منزلت گرا و رابطه هر يك از متغيرهاى مصرف بدون توجه به نقش، تشخصيذيرى و تأثيريذيرى از نفوذ ديخران بر آن صورت كرفته است. نتايج تحقيق و فعاليتهاى آمارى مربوطه با استفاده از ضريب همبستخى يميرسون رابطه منفى و معنى دار بين مصرف بدون توجه به نقش و مصرف منزلتگرا و نيز رابطه مثبت و معنى دار بين متغيرهاى تشخصيذيرى و تأثيريذيرى از نفوذ ديخران با ميزان مصرف منزلت گرا را مورد تأييد قرار داده است. علاوه بر آن، نتايج تحليل مسير ميزان تأثير هر يك از متغيرهاى مصرف بلدون توجه به نقش، تشخصيذيرى و تأثيريذيرى از نفوذ

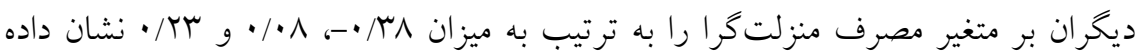
است. درمجموع، نتايج تحقيق با مباحث نظرى صاحبنظران و يافتهاى تحقيقات محققان در اين زمينه قرابت و همخوانى دارد. همجنان كه كلارك و همكاران (Y. (Y) ابراز داشتهاند در الخوى مصرف بدون توجه به نقش صرفاً براى مصرف شخصى و بدون توجه به برستيز آن

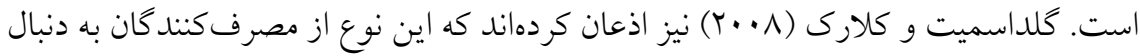
تأييد اجتماعى خريدهايشان هستند. بر اين مبنا، نتايج يزوهش حاضر نيز رابطه منفى بين دو متغير مصرف بلدون توجه نقش و مصرف منزلت گرا را نشان داده است. همجنين، بسيارى از صاحبنظران بر نقش ميزان تأثيريذيرى از نقوذ ديخران بر مصرف (مصرف منزلتگرا) تأكيد كرده و اين امر در تحقيقات متعددى كه توسط يزوهشخران

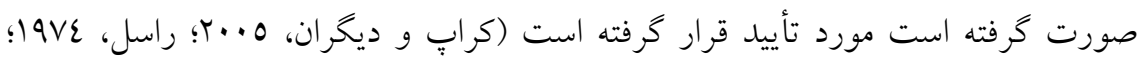

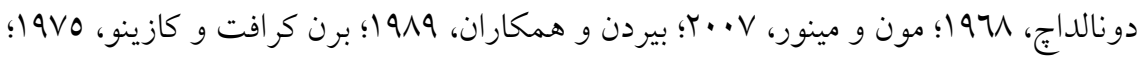

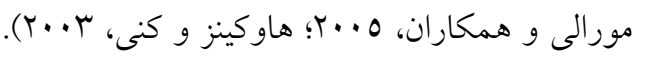
علاوه بر آن، نقش تشخصيذيرى يا تمايل به منحصربهفرد بودن در مصرف منزلت گرا 
Relation of the Consumer Susceptibility to Interpersonal Influence and ...

در رويكردهاى نظرى و يزوهشى صاحبنظران و محققان مختلف مورد تأييد قرار كرفته

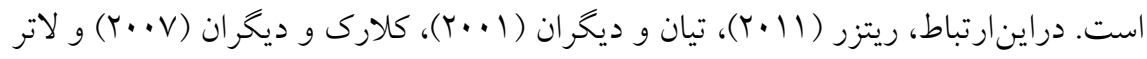

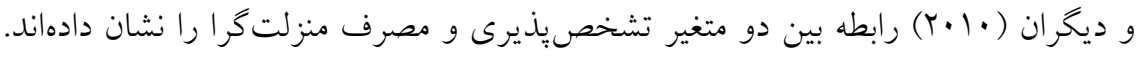

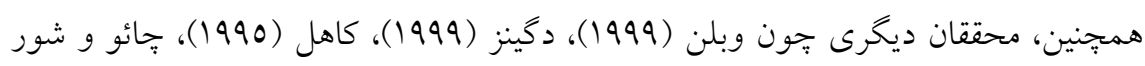

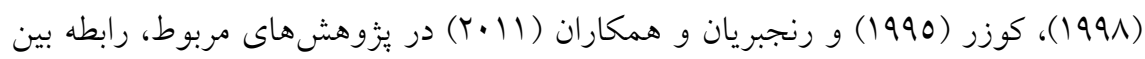
دو متغير فوق را مورد تأييد قرار دادهاند.

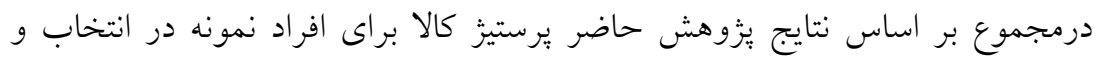

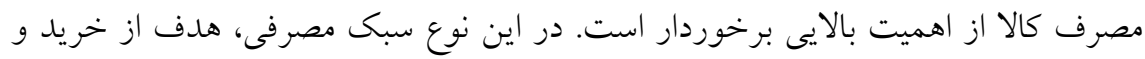

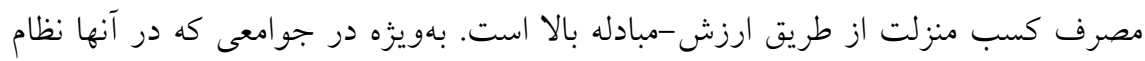
اشرافيت و ثروتمندان قديمى مجبور به تفويض قدرت به ثروتمندان جديد (براى مثال

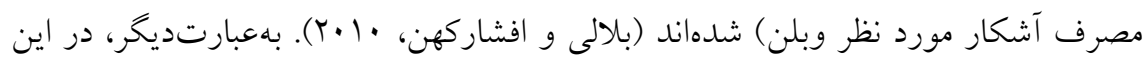

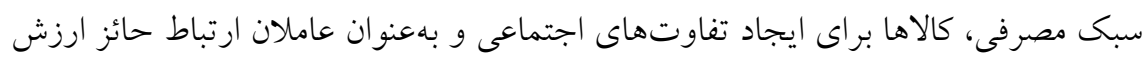

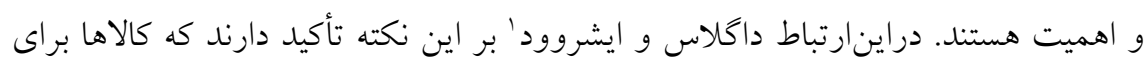

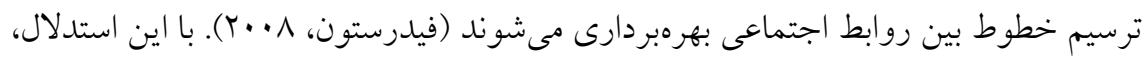

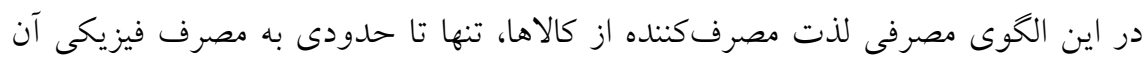

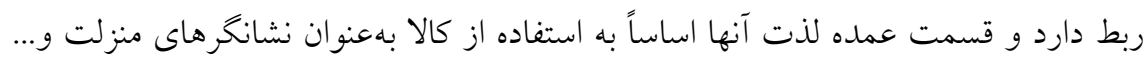

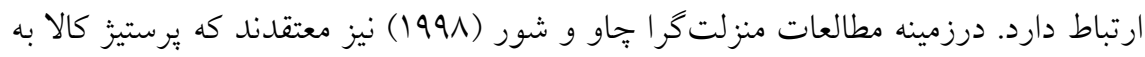

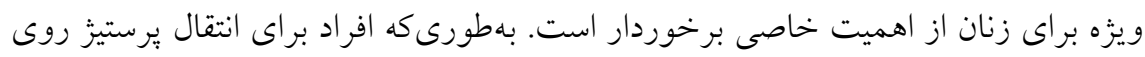
به كالاهايى با نام تجارى معروف با قيمت بالاتر مى آورند.

1. Douglas \& Isherwood 


\section{ملاحظات اخلاقى \\ مشاركت نويسند}

همه نويسند كان در نخارش مقاله مشاركت موثر داشتهاند.

$$
\text { منابع مالى }
$$

بلطور مستقيم حمايت مالى براى انتشار اين مقاله از هيج نهاد و يا سازمانى دريافت

$$
\text { نشده است. }
$$

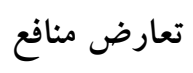

اين مقاله با ساير آثار منتشر شده از نويسندكان مغايرت محتوايى ندارد و اكرجه در

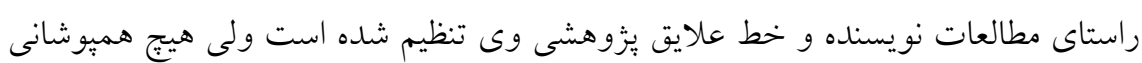

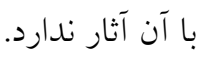

$$
\text { بيروى از اصول اخلاق يزوهش }
$$

در اين مقاله همه حقوق مرتبط با منابع مورد استناد رعايت كرديده و منابع با دقت ذكر برو

شدهاند. 
- Atashpour, H., \& Janatiyan, S. (2013). Psychology of Consumer Behavior. Tehran: RouzAmad. (In Persian)

- Balali, I., \& Afsharkohan, J. (2010). Beauty and Money: Make-up and Surgery. Women's Strategic Studies, 47(12), 99-140. (In Persian)

- Bearden, W. O., Netemeyer, R. G., \& Teel, J. E. (1989). Measurement of consumer susceptibility to interpersonal influence. Journal of Consumer research, 15(4), 473-481.

- Burnkrant, R. E., \& Cousineau, A. (1975). Informational and normative social influence in buyer behavior. Journal of Consumer research, 2(3), 206-215.

- Chao, A., \& Schor, J. B. (1998). Empirical tests of status consumption: Evidence from women's cosmetics. Journal of Economic Psychology, 19(1), 107-131.

- Clark, R. A., Zboja, J. J., \& Goldsmith, R. E. (2007). Status consumption and role-relaxed consumption: A tale of two retail consumers. Journal of Retailing and Consumer Services, 14(1), 45-59.

- Diggins, J. P. (1999). Thorstein Veblen: Theorist of the leisure class: Princeton University Press.

- Eastman, J. K., Goldsmith, R. E., \& Flynn, L. R. (1999). Status consumption in consumer behavior: Scale development and validation. Journal of marketing theory and practice, 7(3), 41-52.

- Goldsmith, R. E., \& Clark, R. A. (2008). An analysis of factors affecting fashion opinion leadership and fashion opinion seeking. Journal of Fashion Marketing and Management: An International Journal, 12(3), 308-322.

- Granbois, D. H. (1968). Improving the study of customer in-store behavior. Journal of Marketing, 32(4_part_1), 28-33.

- Hawkins, D. I., Mothersbaugh, D. L., \& Best, R. J. (2003). Consumer Behavior: Building Marketing Strategy 10/e: McGraw-Hill.

- Jackson, T. (2005). Motivating sustainable consumption. Sustainable Development Research Network, 29(1), 30-40.

- Kahle, L. R. (1995). Observations: Role-relaxed consumers: A trend of the nineties. Journal of Advertising Research, 35(2), 66-72.

- Kouzer, L. (1995). The Life and Thought of the Elders of Sociology (M. Sallasi, Trans). Tehran: Elmi. (In Persian)

- Kropp, F., Lavack, A. M., \& Silvera, D. H. (2005). Values and collective self-esteem as predictors of consumer susceptibility to interpersonal influence among university students. International Marketing Review, 22(1), 7-33. 
- Lalwani, A. K. (2002). Interpersonal orientation of spouses and household purchase decisions: the case of restaurants. Service Industries Journal, 22(1), 184-200.

- Latter, C., Phau, I., \& Marchegiani, C. (2010). The roles of consumers need for uniqueness and status consumption in haute couture luxury brands. Journal of Global Fashion Marketing, 1(4), 206-214.

- Mahmudimimand, M., Vazirzanjani, H. R., \& Khaliliyadegari, M. (2012). Myers-Briggs-MBTI-Personality Testing Dimensions - and Customers' Tendency. New Marketing Research, 7(2), 145-158. (In Persian) - Mai, N. T. T., \& Tambyah, S. K. (2011). ANTECEDENTS AND CONSEQUENCES OF STATUS CONSUMPTION AMONG URBAN VIETNAMESE CONSUMERS. Organizations \& Markets in Emerging Economies, 2(1).

- Moon, J., C, \& Minor, M., S. (2007). Consumer Behavior (A. S. Ardestani, Trans.). Tehran: Farabi. (In Persian)

- Mourali, M., Laroche, M., \& Pons, F. (2005). Individualistic orientation and consumer susceptibility to interpersonal influence. Journal of Services Marketing, 19(3), 164-173.

- Rahmatibadi, E., \& Aghabakhshi, H. (2006). Lifestyle and Youth Identity. Social Welfare, 20(5), 235-254. (In Persian)

- Ranjbarian, B., Zabihzadeh, K., \& Barari, M. (2011). Study patterns of female students in Isfahan University. Woman in Development and Politics, 33(9), 145-170. (In Persian)

- Ritzer, G. (2011). Fundamentals of contemporary sociology theories and its roots (K. Mirza'ie \& A. B. Sarabi, Trans.). Tehran: JameShenasan. (In Persian)

- Sutherland, M. (2008). Commercial Advertising and Consumer Mind: (Commercial Psychology): What works, what does not work and why (S. Ghorbanloo, Trans.). Tehran: Mobaleghan. (In Persian)

- Tian, K. T., Bearden, W. O., \& Hunter, G. L. (2001). Consumers' need for uniqueness: Scale development and validation. Journal of Consumer research, 28(1), 50-66.

- Veblen, T. (2004). The Theories of the Leisure Class (F. Ershad, Trans.). Tehran: Ney. (In Persian)

- Warastehfar, A., \& Mokhtari, H. (2009). Study of the pattern of consumption among women in Tehran. Social Research, 5, 41-62. (In Persian) 